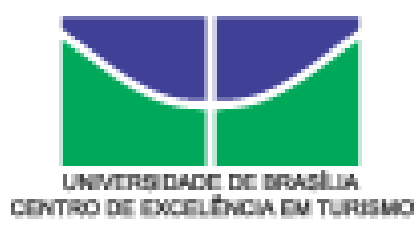

\title{
MARKETING PROMOCIONAL E DE SERVIÇOS NAS INSTITUIÇÕES DE ENSINO DE TURISMO EM BRASÍLIA
}

Autora: ALANA GALLETTI RESENDE

Orientador: WALTER EUSTÁQUIO RIBEIRO

Brasília - 2006 


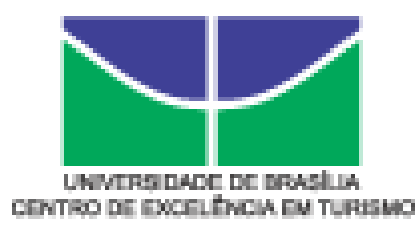

\title{
MARKETING PROMOCIONAL E DE SERVIÇOS NAS INSTITUIÇÕES DE ENSINO DE TURISMO EM BRASÍLIA
}

\author{
Autora: ALANA GALLETTI RESENDE \\ Orientador: Walter Eustáquio Ribeiro \\ Monografia apresentada ao Centro \\ de Excelência em Turismo - CET, da \\ Universidade de Brasília, como requisito \\ parcial para obtenção do certificado de \\ Especialista em Formação de Professores e \\ Pesquisadores em Turismo e Hospitalidade.
}

Brasília - 2006. 
Resende, Alana Galletti.

Marketing Promocional e de Serviços nas Instituições de Ensino de Turismo em Brasília /

Alana Galletti Resende.

Monografia (especialização) - Universidade de Brasília, Centro de Excelência em Turismo.

Brasília - DF, janeiro de 2006.

Área de Concentração: Turismo

Orientador: Walter Eustáquio Ribeiro

1. Marketing Promocional 2. Marketing de Serviços 3. Instituições de Ensino de Turismo. 
UNIVERSIDADE DE BRASÍLIA

Centro de Excelência em Turismo - CET

Curso de Especialização em Formação de Professores e Pesquisadores em Turismo e Hospitalidade

\title{
MARKETING PROMOCIONAL E DE SERVIÇOS NAS INSTITUIÇÕES DE ENSINO DE TURISMO EM BRASÍLIA
}

\author{
ALANA GALLETTI RESENDE
}

\footnotetext{
Maria Tereza Negrão

Doutora

Professora Coordenadora
}
Walter Eustáquio Ribeiro,
Mestre
Professor Orientador

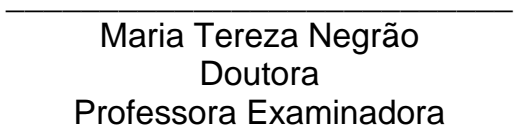

Professora Examinadora

Monografia apresentada ao Centro de Excelência em Turismo - CET, da Universidade de Brasília, como requisito parcial para obtenção do certificado de Especialista em Formação de Professores e Pesquisadores em Turismo e Hospitalidade.

Brasília, janeiro de 2006. 
"O maior obstáculo ao progresso não é a ignorância e, sim, a ilusão de conhecimento." 


\section{DEDICATÓRIA}

Dedico este trabalho ao meu marido, pois seu incentivo foi essencial para esta conquista. 


\section{AGRADECIMENTOS}

A Deus, todo poderoso;

Á Amanda e Bruno, meus amados filhos, por me darem força para batalhar pela vida;

Aos meus pais, por me apoiarem e darem forças em todos os momentos de minha vida;

Ao meu orientador, pela paciência e boa vontade;

Aos funcionários do NDIT/CET, pela colaboração.

A todos, MUITO OBRIGADA! 


\section{RESUMO}

Este trabalho foi realizado após verificar que as instituições de ensino de turismo, em Brasília, estão investindo na qualidade dos cursos ofertados e na conquista de alunos, fazendo uso do marketing promocional e de serviços nesses estabelecimentos. A importância desta pesquisa deve-se ao grande número de faculdades e universidades que estão surgindo, nos últimos anos, oferecendo o curso de turismo. A preocupação com a qualidade total tem feito algumas instituições de ensino de turismo investir na conquista de Certificação Internacional de Qualidade, o ISO 9001, Qualidade Brasil e Qualidade América do Sul, garantindo aos alunos a qualidade reconhecida nacional e internacionalmente. É nesse contexto que vamos mostrar como o marketing promocional e de serviços está inserido nas instituições de ensino de turismo, adaptando-se ao mercado e desenvolvendo novos modelos educacionais.

Palavras-chave: Instituições de Ensino em Turismo, Marketing Promocional e Marketing de Serviços. 


\section{ABSTRACT}

This paper was after carried through to verify that the tourism education institution of Brasilia are investing in the quality of the offered courses and in the conquest of new students, making use of the promotional and service marketing. The importance of this research is a great number of Colleges and Universities are offering tourism course and the focus in total quality has made some institutions of tourism education to invest to be guaranteed Quality International Certifications, such as: ISO 9001:2000, Qualidade Brasil and Qualidade America do Sul, etc. This certified guaranteed to the students quality recognized national and internationally.

Keyword: 1. Tourism Education Institution 2. Promotional Marketing 3. Service Marketing 


\section{JUSTIFICATIVA}

Neste contexto sente-se a necessidade de fazer um estudo sobre como as instituições de ensino em turismo estão se estruturando, buscando alunos e como estão utilizando as estratégias de marketing e suas ferramentas na melhoria dos serviços ofertados.

As instituições de ensino em turismo estão utilizando estratégias de marketing e suas ferramentas para divulgação do estabelecimento e na conquista de alunos. Estão se valendo do marketing promocional e de serviços para a obtenção de resultados positivos, relativos à captação de novos alunos.

A necessidade de profissionalização deste setor requer uma melhoria nos serviços ofertados pelas instituições de ensino, capacitando docentes, estruturando laboratórios e bibliotecas, com conteúdos. Priorizando a formação de seus alunos, colocando profissionais ativos em um mercado de trabalho, em que a concorrência é acirrada, onde a visão de mercado e futuro são primordiais nessa formação. 


\section{OBJETIVO}

O objetivo deste trabalho é demonstrar a visão estratégica e a aplicabilidade das ferramentas do marketing promocional e de serviços nas instituições de ensino de turismo, em relação à captação de alunos e investimentos em serviços oferecidos nestes estabelecimentos. 


\section{SUMÁRIO}

1. INTRODUÇÃO

2. REFERENCIAL TEÓRICO.......................................................................... 03

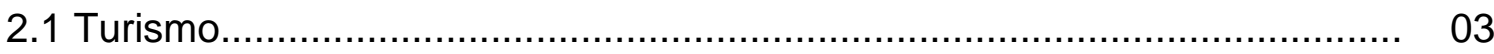

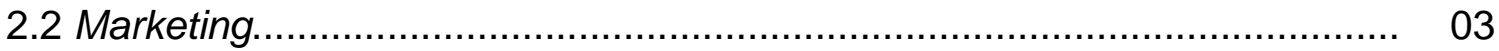

2.3 Necessidade e Desejo.................................................................. 04

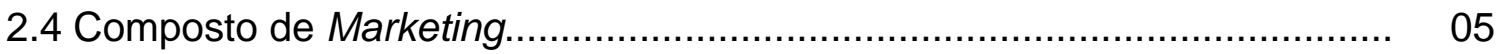

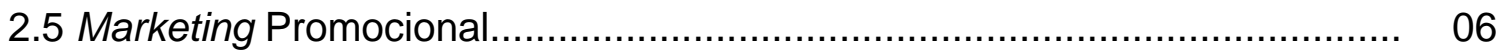

2.6 Marketing de Serviços........................................................................ 07

2.7 Marketing Institucional..................................................................... 08

2.8 Marketing de Relacionamento.................................................................. 08

2.9 Endomarketing ou Marketing Interno..................................................... 09

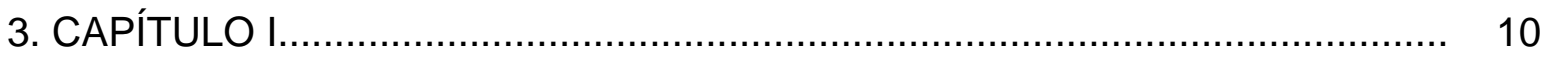

3.1 Histórico do Ensino de Turismo - Contexto Internacional........................... 10

3.2 Histórico do Ensino de Turismo - Contexto Nacional................................. 11

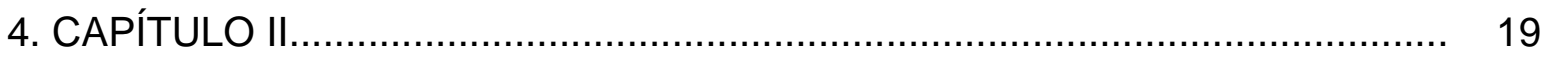

4.1Marketing Promocional nas Instituições de Ensino de Turismo.................... 21

4.2 Marketing de Serviços nas Instituições de Turismo.................................... 23

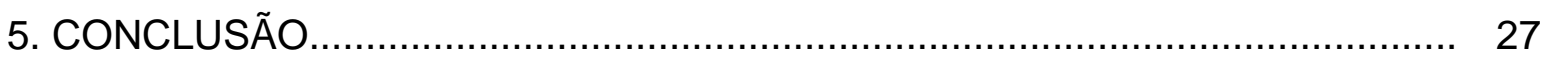

6. REFERÊNCIAS BIBLIOGRÁFICAS......................................................... 28

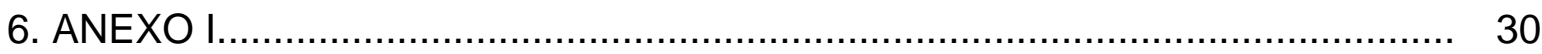

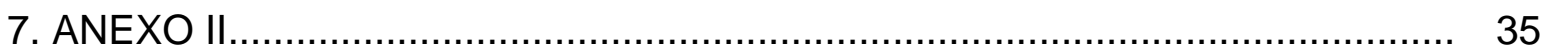

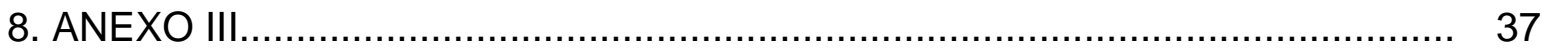




\section{LISTA DE ILUSTRAÇÕES}

Ilustração 1 - Faculdade Alvorada de Educação Física e Desporto - SETEC 30

Ilustração 2 - Instituto de Ensino Superior de Brasília - IESB 30

Ilustração 3 - Instituto de Ensino Superior de Brasília - IESB 31

Ilustração 4 - Faculdade Michelangelo 31

Ilustração 5 - Faculdade de Ciências de Brasília - FACIBRA 32

Ilustração 6 - Universidade Paulista - UNIP 32

Ilustração 7 - Centro Universitário UNIEURO 33

Ilustração 8 - Centro Universitário UNIEURO 33

Ilustração 9 - União Pioneira de Integração Social - UPIS 34

Ilustração 10 - Centro Universitário de Brasília UNICEUB 34

Ilustração 11 - Faculdades Integradas da Terra de Brasília - FTB 35

Ilustração 12 - Centro de Excelência em Turismo - CET 35

Ilustração 13 - Instituto de Ensino Superior de Brasília - IESB 36

Ilustração 14 - União Pioneira de Integração Social - UPIS 36

Ilustração 15 - Faculdade Jesus Maria e José - FAJESU 37 


\section{LISTA DE TABELAS}

Tabela 1 - Cronologia da Abertura de Cursos de Turismo no Brasil 12

Tabela 2 - Distribuição Percentual dos Cursos Oferecidos pelas IES 14

Tabela 3 - Distribuição Percentual dos Cursos que as Instituições Pretendem

Criar

Tabela 4 - Distribuição Percentual das Formas de Gerenciamento de Controle de 16

Qualidade

Tabela 5 - Distribuição Percentual das Formas de Gerenciamento do Controle de

Qualidade

Tabela 6 - Educação Superior, em Brasília: Cursos e Habilitação

Tabela 7 - Relação de Instituições de Ensino de Turismo, em Brasília, que

Promoveram o Marketing Promocional através de Outdoors.

Tabela 8 - Relação de Instituições de Ensino de Turismo, em Brasília, que

Promoveram o Marketing Promocional através de Banners. 


\section{INTRODUÇÃO}

O turismo começou a ganhar vertentes no Brasil, a partir dos anos 1970. O "milagre brasileiro" era acompanhado do surgimento dos cursos de graduação na área.

Ergueu-se academicamente e epistemologicamente. Professores e profissionais da área começaram a ganhar espaço, publicando artigos e fazendo pesquisas para que o fenômeno do turismo fosse acompanhado de estudos específicos. Cursos de graduação, pós-graduação e de mestrado foram se multiplicando, repensando e expandindo o saber sobre o turismo.

Como curso universitário o Turismo no ano de 2005 completou trinta e cinco anos, desde a pioneira Faculdade de Turismo do Morumbi, e hoje com milhares de faculdades e universidades instaladas em todo o Brasil, especializando-se em uma base de conhecimento recente.

O turismo até hoje não é considerado por muitos uma ciência, pois seu estudo de forma científica somente foi iniciado há algumas décadas. No entanto, alguns autores o colocam em uma parte das Ciências Humanas.

A posse do conhecimento no setor de prestação de serviços, especialmente no turismo, garante perante a economia mundial influências que possibilitam a geração de lucros e adaptação frente a novos desafios.

Há um crescente avanço no que diz respeito à educação e à qualidade de ensino no Brasil em relação ao turismo. Diversas instituições de ensino estão se qualificando para atender a um mercado exigente e promissor. Educadores investem na reciclagem e atualização de conhecimentos, e ainda atentam para o fato de que a formação dos discentes deve estar ligada à prestação de serviços eficazes e eficientes, para estes entrarem em um mercado distinto dos demais e bastante competitivo.

O propósito desta pesquisa é identificar os elementos de marketing relacionados com as instituições de ensino em turismo e demonstrar como estão se adequando ao mercado utilizando o marketing promocional e o de serviços. 
Este grande número de instituições de ensino estão investindo na promoção através da mídia, para poderem captar alunos. Estão preocupadas também em ofertar cursos com maior qualidade, inserindo em suas grades curriculares matérias ligadas à prática, hoje indispensável para um profissional da área.

A importância deste trabalho é chamar atenção para o fato de que o curso de turismo está em uma fase de grande crescimento, pois acontecimentos mundiais, como por exemplo, a abertura de novos mercados, está influenciando uma maior troca de conhecimentos entre países, aumentando a demanda de interessados neste curso.

Podemos observar a preocupação destas instituições em conquistar selos, como, por exemplo, o ISO 9001, demonstrando a constante busca pelo aprimoramento do ensino. Outro fator importante são os convênios que estão sendo firmados por estas instituições com faculdades e universidades de outros estados e até mesmo do exterior, possibilitando a troca de conhecimentos e pesquisas e o intercâmbio de professores e alunos.

A metodologia utilizada foi a pesquisa bibliográfica, suporte para o referencial teórico e conceitos relacionados ao tema; pesquisa de campo, selecionando fontes iconográficas para enriquecimento deste trabalho e ainda foi realizada coleta de dados sobre as faculdades e universidades de Brasília, via internet.

No capítulo 1, é apresentado um histórico do ensino do Turismo, em um contexto nacional e internacional; o surgimento dos cursos de turismo; a formação profissional e a preocupação com a qualidade. Uma importante pesquisa, um estudo exploratório, da Professora Rivanda Teixeira, contribuiu para obter uma visão geral dos cursos no Brasil e mostrar como são estruturados e como são geridos os cursos, além de expor razões para serem criados.

No capítulo 2, é apresentada a relação das instituições de ensino de turismo de Brasília, e ainda discriminada quais destas estão utilizando o marketing promocional e o de serviços, através de outdoors, banners e stands. 


\section{REFERENCIAL TEÓRICO}

\subsection{TURISMO}

Definir o termo turismo tem o objetivo de padronizar seu conceito no mundo, mas algumas definições devem ser utilizadas com alguma particularidade, para assim mostrar a real dimensão desse fenômeno.

Um dos conceitos mais utilizados é o da OMT - Organização Mundial do Turismo, que define o Turismo como "o deslocamento para fora do local de residência por período superior a 24 horas e inferior a 60 dias motivado por razões não-econômicas".

Robert McIntosh definiu: "Turismo pode ser definido como a ciência, a arte e a atividade de atrair e transportar visitantes alojá-los e cortesmente satisfazer suas necessidades e desejos" ${ }^{1}$.

Oscar de La Torre (1992) definiu da seguinte forma:

"O turismo é um fenômeno social que consiste no deslocamento voluntário e temporário de indivíduos ou grupos de pessoas que, fundamentalmente por motivos de recreação, descanso, cultura ou saúde, saem de seu local de residência habitual para outro, no qual não exercem nenhuma atividade Iucrativa nem remunerada, gerando múltiplas inter-relações de importância social, econômica e cultural" 2 .

\subsection{MARKETING}

O conceito de marketing é tão essencial para o turismo que foi dessa definição que nasceu o termo "indústria do turismo", quando Kotler definiu que "O mercado do turismo consiste em todos os consumidores potenciais que compartilham de uma necessidade ou desejo específico, dispostos e habilitados para fazer uma troca que satisfaça essa necessidade ou desejo". 3

\footnotetext{
${ }^{1}$ Robert Mcintosh e Shashikant Gupta.

${ }^{2}$ LA TORRE, Oscar de. El turismo, Fenômeno Social, Cidade do México: Fondo de Cultura Econômico, 1992.

${ }^{3}$ KOTLER, Philip. Administração de Marketing. São Paulo: Prentice Hall,2000.
} 
Marketing segundo Kotler e Armstrong (1993) "é um processo social e gerencial através do qual indivíduos e grupos de pessoas obtêm aquilo de que necessitam e desejam, por meio da criação e troca de produtos e valores." 4

Poza Lleida (1993) conceitua marketing de uma forma mais complexa:

"El marketing es uma función de la organización creadora que permite promover el comercio y el empleo, evaluando las necessidades de los clientes e instaurando la investigación y el desarollo que permitan satisfacerlas, siendo su principal base de estudio el consumidor; por um doble motivo: por um lado esa confianza en el progreso tan extendida actualmente y que considera lo más moderno, lo que se acaba de inventar, como mejor y mas perfecto que lo que se empleaba antes $y$, por outro, por esse envejecimiento técnico, obsolescencia, que tienen las cosas, paándose de moda; sobre todo por algo exterior a ellas, por haberse descubierto procedimientos más perfectos y más económicos y que, al ser usados por la competencia, nos dejan fuera de las condiciones de mercado" 5

Marketing é um elo de ligação entre produtores e consumidores que utilizam vários conceitos para interligar necessidades, desejos e demandas; produtos; valor, custo e satisfação; trocas, transações e relacionamentos.

\subsection{NECESSIDADE E DESEJO}

Os conceitos de necessidade e desejo no turismo acabam se confundindo, temos que ter cuidado acerca desta distinção, por exemplo, quando viajamos por obrigação (para tratamento de saúde, negócios, etc) ou para lazer, com o intuito de descansar, para diminuir o stress e recompor forças esgotadas pelo trabalho, estamos falando de necessidade, e quando esta viagem busca lazer em determinados locais que estão na moda, por exemplo, seria desejo.

Philip Kotler e Karen Fox (1994, p.38):

\footnotetext{
${ }^{4}$ KOTLER, Philip; ARMSTRONG, Gary. Princípios do Marketing. Rio de Janeiro: Prentice/Hall do Brasil LTDA, 1993.

${ }^{5}$ LLEIDA, José Maria de La Poza . Marketing Turístico, Barcelona: Oikos - Tau, 1993.
} 
"Uma distinção útil pode ser extraída de necessidades e desejos. Necessidade humana é uma situação de provação de alguma satisfação básica. As pessoas requerem alimento, vestuário, abrigo, segurança, sentimento de posse, auto-estima e algumas outras coisas para sobreviver. Estas necessidades não são criadas pela sociedade ou por especialistas de marketing; elas existem na textura da biologia e da condição humanas.

Desejos humanos são vontades por coisas específicas que suprem necessidades mais profundas. Um jovem americano que deseja estudar medicina começará matriculando-se em uma universidade ou faculdade, em vez de torna-se aprendiz de médico. Dentro da mesma cultura, os desejos individuais variarão em função de diferençiais de experiência de vida e gostos. Uma pessoa pode sentir bem educada e sucedida ao terminar o colégio, enquanto que outra deseja intensamente fazer doutorado em uma universidade de prestígio."

"Instituições que centram em seus programas e falham no entendimento das necessidades dos alunos sofrem de "miopia em marketing". 6 Ficam tão deslumbradas com seus programanais que perdem visão do que os seus alunos, doadores e outros públicos necessitam ou necessitarão no futuro. Instituições educacionais presas fortemente a programas tradicionais, freqüentemente agem como se as necessidades e desejos dos alunos nunca mudassem. Da mesma forma, seu departamento ou associação de ex-alunos pode continuar oferecendo churrascadas antes dos jogos quando o que eles querem é educação continuada. Tais instituições esquecem que devem solucionar um problema do consumidor."

\subsection{COMPOSTO DE MARKETING}

O programa de marketing é formado por um conjunto de estratégias que definem o composto de marketing, ferramentas estas utilizadas por instituições de ensino para se promoverem e alcançar seus objetivos.

\footnotetext{
${ }^{6}$ LEVITT, Theodore. Miopia em marketing. Imaginação de Marketing. São Paulo: Atlas, 1988.
} 
O composto de marketing ou mix de marketing pode ser definido como "a mistura de variáveis de marketing controláveis que a empresa utiliza para atingir o nível desejado das vendas no mercado-alvo". (Kotler, 1984:68.)

McCarthy em 1960 descreveu as variáveis desse mix de marketing, onde se iniciam pela letra "p" no nome em inglês, daí o nome os quatro Ps, que significam: produto, preço, promoção e praça.

Kotler redefiniu os "Ps" como "Cs": consumidor, custo, comunicação e conveniência. O propósito foi converter para o consumidor o marketing de serviços moderno e participar da crescente concorrência do mercado: 7

- Produto significa valor do consumidor (os benefícios percebidos que são oferecidos para atender às necessidades e aos desejos, à qualidade do serviço recebido e ao valor de um bom negócio avaliado com relação à concorrência);

- Preço significa custo (o preço é uma decisão da oferta, custo é o equivalente centrado no cliente também avaliado com relação à concorrência).

- Promoção significa comunicação (englobando todas as formas de diálogo entre produto/consumidor, incluindo as informações e o marketing de relacionamento interativo bidirecional, não apenas a persuasão da venda);

- Praça significa conveniência (em termos do acesso dos consumidores aos produtos que compram).

\subsection{MARKETING PROMOCIONAL}

Segundo Antonio R. Costa e Edison de Gomes Talarico "marketing promocional é o conjunto de atividades empresariais que visam a satisfação das necessidades e dos desejos de um ou vários mercados, através da oferta de produtos, adquiridos por um processo de troca". 8

Talarico descreve que "a promoção deve ser encarada como uma estratégia de marketing e utilizada a partir de uma análise criteriosa da situação mercadológica do produto, para atingir objetivos claramente definidos pela empresa. A análise e o

\footnotetext{
${ }^{7}$ MIDDLETON, Victor T. C.. Marketing de Turismo: teoria e prática/ Victor T. C. Middleton, com Jackie Clarkle. Rio de Janeiro: campus, 2002.

${ }^{8}$ COSTA, Antonio e TALARICO, Edison. Marketing Promocional. São Paulo-SP: Atlas,1996.
} 
planejamento mercadológico propiciarão perfeito diagnóstico do produto, determinando quais as soluções mais adequadas para cada tipo de problema." 9

\subsection{MARKETING DE SERVIÇOS}

A Associação Americana de Marketing define serviços como "aquelas atividades, vantagens ou mesmo satisfações que são oferecidas à venda ou que são proporcionadas em conexão com a venda de mercadorias". ${ }^{10}$

Segundo Victor Middleton, "serviços são produtos comprados através de uma transação de troca que não confere propriedade, mas permite acesso e uso de um serviço, geralmente em um período de tempo específico em um local determinado." 11

Neste conceito devemos observar que ao contrário dos produtos, os serviços devem ser utilizados no momento da compra ou transação, são intangíveis, com isto não é possível visualizar suas características sem antes serem comprados e usados pelos usuários, como por exemplo: um jovem interessado em ingressar em uma faculdade ou universidade, somente consolidará seus desejos, suas necessidades quando começar a freqüentar suas aulas e dispor dos serviços ofertados, como aulas expositivas, laboratórios, secretaria, entre outros.

Outro aspecto no que diz respeito a serviços é o fato de que, quem presta o serviço deverá necessariamente estar em contato com quem recebe, para acompanhar a ligação entre cliente e a instituição de ensino, no exemplo dado anteriormente.

Nesse novo contexto onde o setor de serviços tem crescido rapidamente, profissionais da área sugerem que as instituições de ensino superiores, consigam criar e manter um relacionamento, uma integração constante entre os discente e as respectivas instituições.

\footnotetext{
${ }^{9}$ COSTA, Antonio e TALARICO, Edison. Marketing Promocional. São Paulo-SP: Atlas,1996.

${ }^{10}$ LAS CASAS, Alexandre Luzzi. Marketing de Serviços. São Paulo: Atlas, 1991.

${ }^{11}$ MIDDLETON, Victor T. C.. Marketing de Turismo: teoria e prática/ Victor T. C. Middleton, com Jackie Clarkle. Rio de Janeiro: Campus, 2002.
} 


\subsection{MARKETING INSTITUCIONAL}

Várias instituições têm como objetivo "vender" a própria organização. "O marketing institucional consiste em atividades empreendidas para criar, manter ou alterar as atitudes e comportamentos do público-alvo para com uma organização." 12

\subsection{MARKETING DE RELACIONAMENTO}

Nas principais definições, o marketing de relacionamento é visto como uma maneira diferente de se combinar e administrar ferramentas de marketing que já existem. Stone \& Woodcock (1998, p.3) deram ao marketing de relacionamento a seguinte definição:

"Marketing de relacionamento é o uso de uma ampla gama de técnicas e processos de marketing, vendas, comunicação e cuidado com o cliente para:

1) Identificar os clientes de forma individualizada e nominal;

2) Criar um relacionamento entre a empresa e esses clientes - um relacionamento que se prolongue por muitas transações;

3) Administrar esse relacionamento para o benefício dos clientes e da empresa."

Gordon (1999, p.3) define como "um processo contínuo de identificação de novos valores com clientes individuais e o compartilhamento de seus benefícios durante uma vida toda de parceria. Isso envolve a compreensão, a concentração e a administração de uma contínua colaboração entre fornecedores e clientes selecionados para a criação e o compartilhamento de valores mútuos por meio de interdependência e alinhamento organizacional. O marketing de relacionamento deriva dos princípios do marketing tradicional, ainda que seja diferente. ${ }^{13}$

Marketing de relacionamento, segundo Marcos Cobra, "é uma forma de atrair clientes ou construir alianças de longo prazo com os clientes atuais, com o objetivo permanente de identificar e satisfazer necessidades e desejos." 14

\footnotetext{
${ }^{12}$ KOTLER, Philip; ARMSTRONG, Gary. Princípios de Marketing. Rio de Janeiro: Prentice/Hall do Brasil, 1993.

${ }^{13}$ GORDON, Ian. Marketing de Relacionamento. São Paulo: Futura, 1999.

${ }^{14}$ COBRA, Marcos. Marketing de Serviços. São Paulo, Cobra: 2001.
} 


\subsection{ENDOMARKETING OU MARKETING INTERNO}

Quando o objeto de trabalho são pessoas, tem-se inclusive a preocupação de trabalhar as necessidades e desejos também de quem está operacionando, vendendo o produto ou serviço, o público interno, neste caso o endomarketing surge como uma ferramenta decisiva e bastante importante para as organizações, mais um fator decisivo na conquista de novos clientes, o público externo.

Segundo o Professor Walter Ribeiro, em sua tese de mestrado: ${ }^{15}$

"Endomarketing é o conjunto de atividades humanas dirigidas para satisfazer as necessidades e desejos dos clientes internos (funcionários) e os interesses organizacionais, em um processo de troca em que deve ocorre simbiose equilibrada e consciente para ambas as partes, com resultado sinérgico."

"Endomarketing são projetos e ações que uma empresa deve empreender para consolidar a base cultural do comprometimento dos seus funcionários com o desenvolvimento adequado das suas diversas tecnologias, visando:

- A manutenção de um clima ideal de valorização e reconhecimento das pessoas;

- A obtenção de índices maiores de produtividade, qualidade, com conseqüente redução de custos;

- O estabelecimento de canais adequados de comunicação interpessoal, que permitam a diminuição dos conflitos e insatisfações que possam afetar o sistema organizacional;

- A adequada administração desses conflitos, para que resultem em inovações, com resultados positivos para a empresa e os empregados;

- Estabelecimento da administração participativa;

- A implantação de ações gerenciais preventivas."

\footnotetext{
${ }^{15}$ RIBEIRO, Walter Eustáquio. Endomarketing em instituições financeiras: um estudo de caso do Banco do Brasil. Brasília, 1993. (Dissertação)
} 


\section{CAPÍTULO I}

\subsection{Histórico do Ensino de Turismo - Contexto Internacional}

O contexto internacional vem sofrendo modificações diversas, influenciando uma condição insegura à economia dos países em desenvolvimento, as práticas capitalistas dos países desenvolvidos comandam uma competitividade quase desleal. Dentro desse contexto, o ensino e a cultura, tornam-se fundamentais na formação de profissionais de diversas áreas.

Jean-François Lyortard afirma que "sob a forma de mercadoria informacional indispensável ao poderio produtivo, o saber já é e será um desafio maior, talvez o mais importante, na competição pelo poder" (Lyortard 1986, p.5)

No setor turístico não é diferente o ensino, o saber, é essencial para um bom profissional, a cultura geral é indispensável para a rotina de trabalho, seja em órgãos oficiais de turismo ou em empresas, operadoras e agências de turismo.

A Organização Mundial do Trabalho - OMT pronuncia que o mercado turístico internacional necessita de 11 milhões de profissionais para atender à demanda turística.

Na década de 1960, a formação superior em turismo, nos países europeus, começou a ganhar evidência.

Na Espanha, a partir de 1964 vários problemas técnicos, econômicos e sociais do turismo começaram a ganhar destaque e serem discutidos. O ensino foi regulamentado em 1980, para ingressar no curso de turismo era necessário educação secundária completa, e a duração era em média de três anos, atividades práticas eram e ainda são realizadas no local de trabalho como forma de aprendizagem. O aluno obtém o título de técnico de empresas e atividades turísticas, com valor acadêmico universitário. 


\subsection{Histórico do Ensino de Turismo - Contexto Nacional}

No contexto nacional, em 1928, a Sociedade Brasileira de Turismo, hoje Touring Clube, foi a primeira instituição a ter a iniciativa de organizar o setor, pois o turismo tinha uma estruturação bastante precária, precisando de investimentos tanto do setor privado, quanto do setor público, assim algumas entidades empresariais foram acompanhando e promovendo o turismo no Brasil.

Em 1946, foi criado o Serviço Nacional de Aprendizagem Comercial SENAC, com o objetivo de formar profissionais desde o nível básico, médio até o superior, nas áreas de turismo e hotelaria. Neste mesmo ano também foi criado $O$ Serviço Social do Comércio - SESC, com o objetivo de propiciar atividades de lazer e cultura, e hoje em dia também trabalha com turismo social.

Em 1953, a Associação Brasileira de Agentes de Viagens - ABAV, foi fundada, com isto começaram a organizar congressos em todo o Brasil, sendo discutidos assuntos relacionados à estruturação do turismo brasileiro e suas perspectivas.

Somente a partir de 1968 é que o Brasil teve um impulso na atividade turística, foi inaugurada a Empresa Brasileira de Turismo - EMBRATUR, com a intenção de alavancar o turismo receptivo.

Relativamente recente no Brasil, o Turismo como curso superior, foi criado em 1971, de acordo com Rejowski (1996), os cursos superiores de Turismo, em nível de graduação, surge com a inauguração da Faculdade de Turismo de Morumbi, conhecida hoje como Faculdade Anhembi-Morumbi. Mas no contexto internacional já estava implantado nos países da Europa e América do Norte, onde a formação profissional e a mão-de-obra especializada já estavam operando ativamente no mercado turístico.

Abaixo será mostrado como a partir de 1971 o Brasil começou a se estruturar no ensino do Turismo e Hotelaria. 
Tabela 1 - Cronologia da Abertura de Cursos de Turismo no Brasil.

\begin{tabular}{|c|c|}
\hline \multicolumn{2}{|r|}{ CRONOLOGIA DA ABERTURA DE CURSOS DE TURISMO NO BRASIL } \\
\hline 1971 & $\begin{array}{l}\text { Faculdade de Turismo no Morumbi, São Paulo, Atualmente Faculdade } \\
\text { Anhembi-Morumbi. }\end{array}$ \\
\hline 1973 & $\begin{array}{l}\text { Faculdade de Turismo da Guanabara, Rio de Janeiro; Faculdade Ibero- } \\
\text { Americana, São Paulo; Faculdade de Ciências Exatas, Administrativas e } \\
\text { Sócias, União Pioneira de Integração Social, Brasília; Escola de } \\
\text { Comunicações e Artes da Universidade de São Paulo. }\end{array}$ \\
\hline 1974 & Pontifícia Universidade Católica de Campinas, Campinas. \\
\hline 1975 & Universidade Católica de Pernambuco, Recife. \\
\hline 1976 & $\begin{array}{l}\text { Faculdade Associação Educacional do Litoral Santista, Santos; Faculdade } \\
\text { Capital de Administração e Estatística, São Paulo. }\end{array}$ \\
\hline 1977 & $\begin{array}{l}\text { Reconhecido o curso de turismo da Faculdade Hélio Alonso, Rio de } \\
\text { Janeiro. }\end{array}$ \\
\hline 1978 & $\begin{array}{l}\text { Criado o Centro de Estudos de Administração Hoteleira e Turismo (Ceatel, } \\
\text { ligado ao Senac, São Paulo) }\end{array}$ \\
\hline 1979 & $\begin{array}{l}\text { Curso de Hotelaria da Faculdade de Administração Hoteleira, Caxias do } \\
\text { Sul, RS. }\end{array}$ \\
\hline 1980 & $\begin{array}{l}\text { Associação Educacional Veiga de Almeida, Faculdade de Turismo } \\
\text { Embaixador Paschoal Carlos Magno, rio de Janeiro. Reconhecido o curso } \\
\text { de turismo da PUC-Campinas pela Portaria Ministerial (MEC) no } 335 \text {. }\end{array}$ \\
\hline 1981 & Instituto Cultural Newton Paiva Ferreira, Belo Horizonte. \\
\hline 1984 & $\begin{array}{l}\text { Faculdade de Turismo da Bahia, Salvador; Curso de Hotelaria da } \\
\text { Faculdade Hebraico-Renascença, São Paulo. }\end{array}$ \\
\hline 1985 & $\begin{array}{l}\text { Faculdade de Ciências de Foz do Iguaçu, PR; Universidade de Fortaleza, } \\
\text { CE. }\end{array}$ \\
\hline 1989 & $\begin{array}{l}\text { O Senac/Ceatel cria o curso técnico de Turismo (nível secundário) com } \\
\text { um ano de duração. Instalou o seu primeiro curso regular de Tecnologia } \\
\text { em Hotelaria. }\end{array}$ \\
\hline
\end{tabular}

Fonte: Revista Turismo - Artigo: O Ensino do Turismo e a Formação Profissional em Turismo 
De acordo com Ansarah e Rejowski (1994), no ano de 1994, existiam 33 cursos superiores de Turismo/Hotelaria no Brasil, sendo 29 de Turismo, dois de Hotelaria e dois em Turismo e Hotelaria, nos quais a maioria desses cursos estavam em faculdades e universidades privadas.

O crescimento do número de cursos superiores de Turismo ou de Turismo e Hotelaria, no Brasil, conforme dados do MEC/SESU/DEDES (2000), até 1998 havia 157 cursos, sendo 119 cursos de Turismo e 38 de Hotelaria/Administração Hotelaria. Em 1999, 39 cursos foram autorizados, sendo 37 de Turismo e dois de Hotelaria/Administração Hotelaria. Em 2000, O número voltou a crescer expressivamente, pois 88 novos cursos foram autorizados pelo MEC, sendo 69 de Turismo e dezenove de Hotelaria/Administração Hoteleira. O total informado pelo MEC era de 284 cursos, sendo 225 de Turismo e 59 de Hotelaria/Administração Hoteleira. $^{16}$

Verifica-se que 94\% destes cursos são ofertados por instituições privadas, e apenas 6\% por instituições públicas. Entre as públicas cerca de 3\% são federais, 2\% estaduais e 1\% municipal. Praticamente todos os 225 cursos de Turismo, são de Turismo apenas, mas cerca de 2,2\% deles oferecem um combinado de Turismo e Hotelaria, 63\% são cursos de Administração com habilitação em Administração Hoteleira. $^{17}$

Dados da ABDETH (Associação Brasileira dos Dirigentes das Escolas de Turismo e Hotelaria), publicados na Folha de São Paulo, em 27 de maio de 2001, mostrava que, 130 instituições ofereciam cursos de hotelaria e 250 de turismo em todo o país. Em dez anos, no Brasil, o número de cursos de hotelaria em nível superior, cresceu $1.757 \%$ e o de cursos de turismo, $900 \%$. ${ }^{18}$

Conforme pesquisa realizada, em maio de 2003, pela Professora Rivanda Teixeira, em que foram aplicados questionários compostos de perguntas abertas e fechadas, encaminhados através do correio para todos os chefes/coordenadores de cursos de Turismo /Hotelaria do Brasil, de acordo com lista baseada em informações do MEC/SESU (dados de 1998) e EMBRATUR. As instituições de ensino superior que participaram desta pesquisa ofertavam vários cursos na área de turismo e foi

\footnotetext{
${ }^{16}$ TEIXEIRA, Rivanda. Artigo: Ensino Superior em Turismo e Hotelaria no Brasil: Um Estudo Exploratório, p.2

${ }^{17}$ Id. Ibid., p. 2.

${ }^{18}$ Id. Ibid., p. 2.
} 
observado que, na grande maioria, eram cursos de bacharelado em turismo, em hotelaria ou em turismo e hotelaria, conforme tabela a seguir.

Tabela 2 - Distribuição percentual dos cursos oferecidos pela IES ${ }^{19}$

\begin{tabular}{|c|c|c|}
\hline Cursos & $\begin{array}{l}\text { Freqüência } \\
\text { Absoluta }\end{array}$ & $\begin{array}{l}\text { Freqüência } \\
\text { Relativa }\end{array}$ \\
\hline Turismo & 33 & 58,9 \\
\hline Hotelaria/Administração Hoteleira & 5 & 8,9 \\
\hline Turismo e Hotelaria/Administração Hoteleira & 3 & 5,4 \\
\hline Administração com habilitação em Administração Hoteleira & 2 & 3,8 \\
\hline Administração em Turismo & 1 & 1,7 \\
\hline Turismo, Planejamento e Gestão Turística/Hoteleira & 1 & 1,7 \\
\hline $\begin{array}{l}\text { Tecnólogo/Seqüencial/Politécnico (Turismo/Administração } \\
\text { Hoteleira/Alimentos e Bebidas/Turismo e Meio Ambiente) }\end{array}$ & 9 & 16,0 \\
\hline Gastronomia & 1 & 1,7 \\
\hline Lazer e Eventos & 1 & 1,7 \\
\hline Total & 56 & 100,0 \\
\hline
\end{tabular}

Obs: A questão admitiu mais de uma resposta

Além destes cursos também foi constatado o oferecimento de cursos de pósgraduação lato sensu, como gestão de empreendimentos turísticos, gestão de negócios turísticos e hoteleiros, ecoturismo, ecologia e turismo, gestão de empreendimentos turísticos, marketing e turismo, e cursos stricto sensu como, por exemplo, mestrado em administração de empresas turísticas.

\footnotetext{
${ }^{19}$ Id. Ibid., p. 8.
} 
Observa-se nestas instituições um aumento nos números de candidatos que procuram os processos seletivos destas, nos últimos três anos aumentou em 72,5\%, permaneceu o mesmo em $25 \%$ e diminui em $2,5 \% .^{20}$

A explicação para esse aumento de alunos está na melhoria da qualidade dos cursos e a percepção de que o mercado do Turismo vem crescendo nos últimos anos de forma estruturada. E a diminuição está vinculada à questão financeira, pois é crescente a inadimplência nestes cursos, por volta de 20 a 30\%.

Foi identificada nestas instituições a intenção de abertura de novos cursos, como, por exemplo, novas graduações, cursos de extensão, pós-graduação, mestrados e doutorados, mostradas na tabela a seguir.

Tabela 3 - Distribuição percentual dos cursos que as instituições pretendem criar ${ }^{21}$

\begin{tabular}{|l|c|c|}
\hline \multicolumn{1}{|c|}{ Cursos } & $\begin{array}{l}\text { Freqüência } \\
\text { Absoluta }\end{array}$ & $\begin{array}{l}\text { Freqüência } \\
\text { Relativa }\end{array}$ \\
\hline Extensão/Pós-Graduação Lato Sensu & 13 & 32,5 \\
\hline $\begin{array}{l}\text { Cursos de Graduação } \\
\text { (Turismo/Hotelaria/Gastronomia/Gestão e Lazer) }\end{array}$ & 11 & 27,5 \\
\hline Cursos Seqüenciais & 6 & 15,0 \\
\hline Curso Técnico (Guia Turístico/Hotelaria/Lazer) & 4 & 10,0 \\
\hline Mestrado & 3 & 7,5 \\
\hline Educação à distância & 1 & 2,5 \\
\hline Doutorado & 44 & - \\
\hline Total & 40 & 100,00 \\
\hline Total de respondentes & & \\
\hline
\end{tabular}

Obs: A questão admitiu mais de uma resposta

As freqüências relativas foram calculadas com base no número de respondentes, 40 .

${ }^{20}$ TEIXEIRA, Rivanda. Artigo: Ensino Superior em Turismo e Hotelaria no Brasil: Um Estudo Exploratório, p.12

${ }^{21}$ Id. Ibid., p. 14. 
Em relação à qualidade dos cursos de graduação em Turismo e Hotelaria, a pesquisa da Professora Rivanda Teixeira deixou claro que as instituições de ensino superiores questionadas trabalham de forma preocupada e assistida no que tange à qualidade desses cursos, conforme apresentado na tabela abaixo.

Tabela 4 - Distribuição percentual das formas de gerenciamento de qualidade ${ }^{22}$

\begin{tabular}{|c|c|c|}
\hline Categorias & $\begin{array}{l}\text { Freqüência } \\
\text { Absoluta }\end{array}$ & $\begin{array}{l}\text { Freqüência } \\
\text { Relativa }\end{array}$ \\
\hline $\begin{array}{lll}\text { Investimentos } & \text { em } & \text { docentes } \\
\text { (qualificação/atualização/contratação) } & \end{array}$ & 12 & 30,0 \\
\hline Com preocupação/não respondeu diretamente & 7 & 17,5 \\
\hline Busca permanente /contínua & 7 & 17,5 \\
\hline Política de qualidade/avaliação institucional & 7 & 17,5 \\
\hline $\begin{array}{l}\text { Inovação métodos de ensino/projeto } \\
\text { pedagógico/atualização do currículo }\end{array}$ & 6 & 15,0 \\
\hline Biblioteca/laboratórios/hotel escola/empresa júnior & 4 & 10,0 \\
\hline Não investe em qualidade & 1 & 2,5 \\
\hline Total & 44 & - \\
\hline Total de respondentes & 40 & 100,0 \\
\hline
\end{tabular}

Obs: A questão admitiu mais de uma resposta.

As freqüências relativas foram calculadas com base no número de respondentes, 40 .

Foram pesquisadas também as formas de controle de qualidade adotadas pelas instituições de ensino superior, realizadas de várias formas: semestral, anual, através de questionários, amostral, em reuniões ou informalmente, nos quais estão relacionadas a seguir.

\footnotetext{
${ }^{22}$ TEIXEIRA, Rivanda. Artigo: Ensino Superior em Turismo e Hotelaria no Brasil: Um Estudo Exploratório, p.16
} 
Tabela 5 - Distribuição percentual das formas de gerenciamento do controle de qualidade ${ }^{23}$

\begin{tabular}{|l|c|c|}
\hline \multicolumn{1}{|c|}{ Formas de controle } & $\begin{array}{l}\text { Freqüência } \\
\text { absoluta }\end{array}$ & $\begin{array}{l}\text { Freqüência } \\
\text { Relativa }\end{array}$ \\
\hline Avaliação dos professores pelos alunos & 37 & 92,5 \\
\hline $\begin{array}{l}\text { Avaliação institucional/coordenação de } \\
\text { qualidade/programa de qualidade }\end{array}$ & 11 & 17,5 \\
\hline Não é sistematizada/baseada em observações/subjetiva & 7 & 10,0 \\
\hline Pesquisa de egressos & 4 & 10,0 \\
\hline Avaliação externa & 4 & 5,0 \\
\hline Em processo de elaboração & 5 & 10,0 \\
\hline Através de reuniões com alunos/docentes & 4 & - \\
\hline Total de respostas & 69 & 100,00 \\
\hline Total de respondentes & 40 & \\
\hline
\end{tabular}

Obs: A questão admitiu mais de uma resposta

As freqüências relativas calculadas com base no número de respondentes, 40.

A profissionalização da atividade turística constitui um grande desafio, devido inclusive ao aprofundamento dos efeitos da globalização e abertura de novos mercados consumidores.

O desempenho das instituições de ensino em turismo é muito importante, uma vez que funcionam como elemento democratizador do conhecimento necessário ao bom desempenho das atividades turísticas.

As faculdades e universidade têm um importante papel, à medida que nivelam o conhecimento esperado pelo mercado, despertam o espírito empreendedor e realizam trocas de experiências entre os estudantes e os professores.

${ }^{23}$ Id.2 Ibid., p. 17. 
O bacharel em turismo tem várias funções como, por exemplo, o planejamento de atividades turísticas, melhoria e aproveitamento de espaços públicos, naturais e de patrimônios históricos, promoção de eventos, congressos exposições, entre outros. 


\section{CAPÍTULO II}

A partir dos anos 90, em Brasília, começou a crescer o número de instituições de ensino em turismo, foram criadas mais de cinco faculdades e universidades, oferecendo cursos superiores de turismo e ainda foi inaugurado um centro de excelência em turismo, qualificando profissionais de diversas áreas oferecendo pós-graduação e mestrado.

Abaixo estão relacionadas as instituições de ensino que ofertam cursos de turismo em Brasília:

Tabela 6 - Educação Superior, em Brasília: Cursos e Habilitação.

\begin{tabular}{|c|c|}
\hline INSTITUIÇÃO & CURSO/HABILITAÇÃO \\
\hline $\begin{array}{l}\text { Associação Península Norte de Educação, Ciência e } \\
\text { Cultura - CECAP }\end{array}$ & Turismo \\
\hline Centro de Excelência em Turismo - CET/UnB & $\begin{array}{l}\text { Pós-graduação (Turismo, } \\
\text { Hotelaria e Gastronomia) }\end{array}$ \\
\hline Centro Universitário de Brasília UniCEUB & Turismo \\
\hline Centro Universitário UNIEURO & Turismo \\
\hline $\begin{array}{l}\text { Centro Universitário Planalto do Distrito Federal - } \\
\text { UNIPLAN }\end{array}$ & $\begin{array}{l}\text { - Turismo; } \\
\text { - Curso Superior de } \\
\text { Tecnologia em Eventos } \\
\text { (Área } \\
\text { Turismo e Hospitalidade); } \\
\text { - Curso Superior de } \\
\text { tecnologia em Turismo } \\
\text { Receptivo A Área } \\
\text { Profissional: Turismo e } \\
\text { Hospitalidade). }\end{array}$ \\
\hline $\begin{array}{l}\text { Faculdade Alvorada de Educação Física e Desporto - } \\
\text { SETEC }\end{array}$ & Turismo \\
\hline Faculdade Cenecista de Brasília - FACEB & Turismo \\
\hline $\begin{array}{l}\text { Faculdades Eurobras - Estudos } \text { Universitários } \\
\text { Regionais Brasileiros - EUROBRAS }\end{array}$ & Turismo \\
\hline Faculdade de Ciências de Brasília - FACIBRA & Turismo \\
\hline $\begin{array}{l}\text { Faculdade de Ciências Sociais e Tecnológicas - } \\
\text { FACITEC }\end{array}$ & Turismo \\
\hline
\end{tabular}




\begin{tabular}{|l|l|}
\hline Faculdades Integradas da Terra de Brasília - FTB & Turismo \\
\hline Instituto de Educação Superior de Brasília - IESB & Turismo \\
\hline Universidade Católica de Brasília - UCB & Turismo à Distância \\
\hline Universidade Paulista - UNIP & $\begin{array}{l}\text { Curso Superior de } \\
\text { Tecnologia Gestão de } \\
\text { Empreendimentos de } \\
\text { Turismo - Hotelaria }\end{array}$ \\
\hline União Pioneira de Integração Social - UPIS & $\begin{array}{l}\text { Turismo } \\
\text { Turismo e Hotelaria - } \\
\text { Universidade Salgado de Oliveira - UNIVERSO }\end{array}$ \\
\hline
\end{tabular}

Fonte: Ministério da Educação - Educação Superior - Cursos e Instituições

As Instituições de Ensino de Turismo, em Brasília, estão inovando usando práticas modernas de marketing. Estão aplicando as ferramentas do marketing para se promoverem e oferecerem melhores serviços.

Essas instituições também estão sendo orientadas para o marketing, isto significa que, estão se preocupando com as necessidades e os desejos de seus clientes e com a satisfação destes em relação a preços, serviços ofertados e qualidade dos cursos.

Philip Kotler e Karen F. A. Fox (1994, p.28), dizem que:

"Uma orientação de marketing ou orientação societal de marketing representa que a principal tarefa da instituição é determinar as necessidades, desejos e interesses de seus consumidores e adaptar-se para entregar satisfações que preservem ou enriqueçam o bem estar e interesses a longo prazo desses consumidores e da sociedade."

Muito embora a maioria das instituições se utilizem dessa orientação de marketing, outras não o fazem por motivos de tradição ou cultura organizacional. Podem estar sendo orientadas para se preocuparem com seu produto (orientação 
de produto), ou com sua eficiência (orientação de produção) ou com a escolha de programas por seus alunos (orientação de venda).

Orientação de produto tem como proposta oferecer programas bons para seus clientes, por exemplo, renovar a grade curricular para se adequar ao perfil dos alunos e as perspectivas de mercado.

Orientação de produção seria manter uma mesma grade curricular por anos, sem se preocupar com as necessidades e desejos de seus clientes, e sim com as exigências do processo de produção, não modificando o que estiver dando certo.

Orientação de venda propõe o aumento no setor de vendas, desenvolvendo programas mais atraentes, aumentando a propaganda e a venda pessoal.

Nos dias atuais é percebido que as instituições de ensino de turismo estão se preocupando com o declínio no número de matrículas a cada semestre, a saída de alunos durante o ano letivo e ainda a grande competitividade neste mercado, são fatores que estão influenciando as faculdades e universidades a se enquadrarem às novas exigências de mercado.

Uma instituição que responde ao mercado se esforça para atender as expectativas de seus clientes, satisfazendo suas necessidades e desejos, dentro de uma planilha de orçamento, implementando programas para alcançar esse nível de satisfação pretendida.

Uma instituição que não responde ao mercado tem seu fim certo e programado, pois essa adota uma política burocrática, preocupando-se com as rotinas de trabalho e com a hierarquização, transformando a instituição em uma máquina impessoal.

\subsection{Marketing Promocional nas Instituições de Ensino de Turismo}

Neste processo de inserção no mercado, o marketing é visto como uma ferramenta obrigatória nestas instituições, onde são analisados itens como: as oportunidades de mercado, o posicionamento, a diferenciação e a promoção, levando-as a terem visões estratégicas para competirem neste mercado em que a imagem e a qualidade são essenciais. 
A propaganda está presente em todas as formas de expressão que constituem o relacionamento humano. Ela deve ser analisada por meio de suas expressões verbais e não verbais, ou seja, não só pelo que se fala, mostra e escreve, mas por todas as ações que representam a imagem de, por exemplo, uma instituição de ensino em turismo.

A propaganda cria preferência para a marca do serviço anunciado. Sob esse aspecto "a propaganda é uma tentativa de influenciar a opinião e a conduta da sociedade, de tal modo que as pessoas adotem uma opinião e uma conduta determinada". (Jean Domenach) ${ }^{24}$

A propaganda consiste de formas impessoais de comunicação conduzidas através de mídia paga, sob patrocínio identificado ou não. A propaganda pode tomar muitas formas e atender muitos propósitos. Envolve mídias variadas como revistas, jornais, rádio, televisão, outdoors, banners, entre outros.

As faculdades e universidades, em Brasília, com a crescente concorrência começaram a adotar a propaganda através de outdoors, banners e stands localizados em shopping centers, como ilustrado nos anexos I, II e III, deste trabalho.

Abaixo estão relacionadas as instituições de ensino em turismo que no mês de dezembro/2005 e janeiro/2006, investiram no marketing promocional por meio de outdoors:

Tabela 7 - Relação de Instituições de Ensino de Turismo, em Brasília, que Promoveram o Marketing Promocional através de Outdoors.

\begin{tabular}{|l|l|}
\hline \multicolumn{1}{|c|}{ Anexo I } & \multicolumn{1}{c|}{ Instituição de Ensino de Turismo } \\
\hline Ilustração 1 & Faculdade Alvorada de Educação Física e Desporto - SETEC \\
\hline Ilustração 2 e 3 & Instituto de Educação Superior de Brasília - IESB \\
\hline Ilustração 4 & Faculdade Michelangelo \\
\hline Ilustração 5 & Faculdade de Ciências de Brasília - FACIBRA \\
\hline Ilustração 6 & Universidade Paulista - UNIP \\
\hline
\end{tabular}

${ }^{24}$ COBRA, Marcos. Estratégias de Marketing de Serviços. São Paulo: Cobra, 2001. 


\begin{tabular}{|l|l|}
\hline Ilustração 7 e 8 & Centro Universitário UNIEURO \\
\hline Ilustração 9 & União Pioneira de Integração Social - UPIS \\
\hline Ilustração 10 & Centro Universitário de Brasília UNICEUB \\
\hline
\end{tabular}

Algumas instituições também investiram nos meses de dezembro/2005 e janeiro/2006, em propaganda, através de banners, localizados em paradas de ônibus e nas áreas próximas às sedes, listadas no quadro a seguir:

Tabela 8 - Relação de Instituições de Ensino de Turismo, em Brasília, que Promoveram o Marketing Promocional através de Banners.

\begin{tabular}{|l|l|}
\hline \multicolumn{1}{|c|}{ Anexo II } & \multicolumn{1}{|c|}{ Instituição de Ensino de Turismo } \\
\hline Ilustração 11 & Faculdades Integradas da Terra de Brasília - FTB \\
\hline Ilustração 12 & Centro de Excelência Em Turismo - CET \\
\hline Ilustração 13 & União Pioneira de Integração Social - UPIS \\
\hline Ilustração 14 & Instituto de Educação Superior de Brasília - IESB \\
\hline
\end{tabular}

\subsection{Marketing de Serviços nas Instituições de Ensino de Turismo}

As instituições de ensino de turismo estão se adaptando às novas tendências do mercado, nas quais precisam ofertar qualidade de serviços para atrair egressos aos seus cursos.

A tendência mundial em diversos países é o crescimento do papel do setor se serviços na economia como um todo. Portanto, o investimento em tecnologia de serviços de marketing, deve ser ascendente, sobretudo como um fator de diferenciação estratégica. Com o fim da era da fidelidade do cliente, as empresas estarão buscando formas inusitadas para a realização de sonhos dos consumidores, procurando retê-los como clientes. E isto representará um direcionamento para os 
valores intangíveis dos serviços no sentido da realização das fantasias dos consumidores, buscando realizar desejos explícitos e ocultos. ${ }^{25}$

Marcos Cobra (2001, p.18) retrata a importância de um cliente:

"Mais importante do que ter um produto ou serviço para ofertar, é ter um cliente para satisfazer. Com o cliente na mão, um gerente de marketing, pode desenvolver um serviço sob medida para esse cliente. Para reter um cliente é preciso proporcionar diversas conveniências, com o objetivo de tornar esse cliente fiel. Uma vez que, cliente satisfeito é cliente fiel. O difícil é desenvolver um elenco de atividades que mantenham esse cliente satisfeito, pois há uma regra que diz que um cliente nunca está totalmente satisfeito. A conveniência de ser atendido com cortesia e magia. Muitas vezes uma relação cessa, quando a empresa de serviços, transforma aquele que deveria ser um momento mágico em um momento trágico. ..."

O ponto principal ao oferecer serviços com qualidade é o gerenciamento de atividades como: a criação de um apoio adequado por parte dos gerentes e também das funções de suporte, assim como dos investimentos em tecnologia e dos sistemas operacionais administrativos.

Através da função de marketing externo, envolvendo os esforços do marketing tradicional, como pesquisa de mercado, vendas pessoais, publicidade, mala direta, promoção de vendas, estabelecimento de preços e relações públicas, a organização faz promessas que, espera-se, correspondam às necessidades e desejos pessoais do grupo-alvo de clientes. ${ }^{26}$

Christian Grönroos (1995, p. 325), demonstrou uma visão geral de uma estratégia orientada para o mercado, através do gráfico ilustrado abaixo:

\footnotetext{
${ }^{25}$ COBRA. Marcos. Estratégias de Marketing de Serviços. São Paulo: Cobra, 2001.

${ }^{26}$ GRÖNROOS, Christian. Marketing: Gerenciamento e Serviços. A competição por serviços na Hora da Verdade. Rio de Janeiro: Campus, 1995.
} 


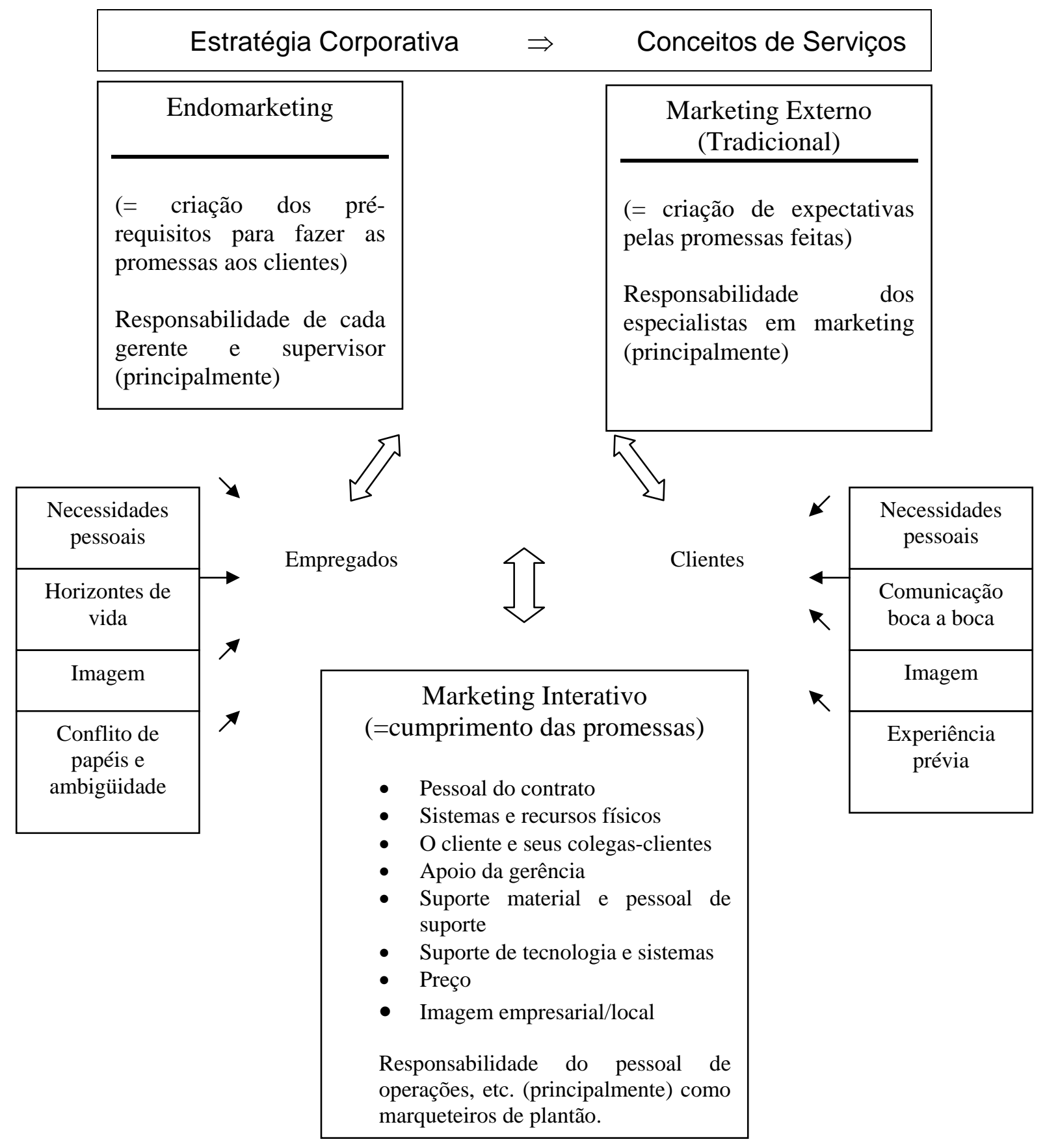

Para implementação de qualquer ação tática ou estratégica, é necessária a presença de talentos humanos, profissionais competentes que visem, em conjunto com a empresa, oferecer produtos e serviços com qualidade.

As faculdades e universidades de Brasília estão oferecendo serviços diversos em suas entidades, como por exemplo: 
- grades curriculares direcionadas ao mercado de trabalho;

- laboratórios que reproduzem a realidade vivida em agências de viagens e hotéis;

- pesquisas de campo, para integração total com matérias teóricas;

- viagens a pólos turísticos para serem estudados na prática.

Estão buscando, ainda uma diferenciação em suas instituições, buscando convênios com faculdades e universidades de outros estados e do exterior para aprimorar o ensino e a troca de conhecimentos e pesquisas. 


\section{CONCLUSÃO}

Com o crescente número de instituições de ensino de turismo, em Brasília, surgiu a necessidade de investimentos nessas instituições, qualificação dos serviços e a preocupação em atender as necessidades, os desejos e os interesses desse mercado-alvo.

Foi possível identificar com a realização deste trabalho que muitas faculdades e universidades de turismo estão se preocupando em atender as necessidades e desejos de seus clientes, cada vez mais exigentes.

A comunicação com o público é uma das formas mais bem sucedidas na relação de vendas de bens e serviços. Um produto para ser comprado, precisa ser conhecido de uma forma positiva, e são essenciais neste momento, o conhecimento, a imagem do produto e as informações transmitidas.

O uso do marketing por essas instituições tem o propósito de promoção e propaganda para criar e manter a demanda. Planejando e administrando as relações de troca com seu público-alvo essas instituições desenvolvem programas viáveis, com preços e comunicação eficazes.

O marketing promocional utilizado por essas instituições tem o objetivo de alcançar um público-alvo através da imagem. Outdoors e banners foram as formas de mídia mais utilizadas nesta promoção, foram colocados em pontos estratégicos da cidade. As avenidas e ruas onde podiam ser visualizados eram escolhidas conforme a movimentação de automóveis, quanto maior a circulação mais públicos eram alcançados.

O marketing de serviços demonstra como a visão estratégica e a aplicabilidade das ferramentas de marketing e sua interação com o cliente, podem proporcionar as instituições uma retenção maior no número de alunos, oferecendo serviços que visam às necessidades e desejos de seus consumidores.

Portanto foi constatado que as instituições de ensino de turismo, em Brasília, estão obtendo sucesso, interligando qualidade na prestação de serviços e estratégias de marketing, em seu marketing promocional e de serviços para obter uma imagem positiva perante seus clientes. 


\section{REFERÊNCIAS BIBLIOGRÁFICAS}

ANSARAH, M. G. dos Reis e Rejowski, M..Cursos Superiores de Turismo e Hotelaria no Brasil. In: Turismo e Análise. São Paulo: ECA/USP, 1994.

ANDRADE, José Vicente. Gestão em Lazer e Turismo. Belo Horizonte, MG: Autêntica, 2001.

COBRA, Marcos. Estratégias de Marketing de Serviços. São Paulo: Cobra, 2001.

COSTA, Antonio e TALARICO, Edison. Marketing Promocional. São Paulo-SP: Atlas, 1996.

FILHO, Domingos Parra e SANTOS, João Almeida. Apresentação de Trabalhos Científicos - Monografia: TCC, Teses, Dissertações. São Paulo: Futura, 2000.

GORDON, Ian. Marketing de Relacionamento. São Paulo: Futura, 1999.

GRÖNROOS, Christian. Marketing: gerenciamento e serviços: a competição por serviços na hora da verdade. Rio de Janeiro: Campus, 1995.

LAS CASAS, Alexandre Luzzi. Marketing de Serviços. São Paulo: Atlas, 1991.

LLEIDA, José Maria de La Poza. Marketing Turístico. Barcelona: Oikos - Tau, 1993.

MELGAR, Ernesto Guilenea. Fundamentos de Planejamento e Marketing em Turismo. São Paulo: Contexto, 2001.

MIDDLETON, Victor T. C.. Marketing de Turismo: teoria e prátical Victor T. C. Middleton, com Jackie Clarkle; Tradução [da nova edição revista] de Fabíola Vasconcelos. 3a Edição. Rio de Janeiro: Campus, 2002.

KOTLER, Philip. Administração de Marketing. São Paulo: Atlas, 1996.

KOTLER, Philip e ARMSTRONG, Gary. Princípios de Marketing. Rio de Janeiro: Prentice/Hall do Brasil, 1993.

KOTLER, Philip e FOX, Karen F. A. Marketing Estratégico para Instituições Educacionais. São Paulo: Atlas, 1994. 
LA TORRE, Oscar de. El Turismo, Fenômeno Social. Cidade do México: Fondo de Cultura Econômico, 1992.

REJOWSKI, M. Turismo e Pesquisa Científica. São Paul:. Papirus, 1996.

RUSCHMANN, Doris. Turismo no Brasil. Análise e Tendências. 1ª Edição. Barueri, SP: Manole, 2002.

TRIGO, Luiz Gonzaga Godoi. Turismo e Qualidade. Tendências Contemporâneas. Campinas, SP: Papirus 1996.

_. Cronologia do Turismo no Brasil. São Paulo CTI/Terra.

RIBEIRO, Walter Eustáquio. Endomarketing em instituições financeiras: um estudo de caso do banco do Brasil. Brasília, 1993. (Dissertação)

ZARDO, Eduardo Flávio. Marketing Aplicado ao Turismo: ferramentas de marketing para empresas de turismo e destinos turísticos. São Paulo, SP: Roca, 2003. 


\section{ANEXO I}

Ilustração 1 - Faculdade Alvorada de Educação Física e Desporto - SETEC

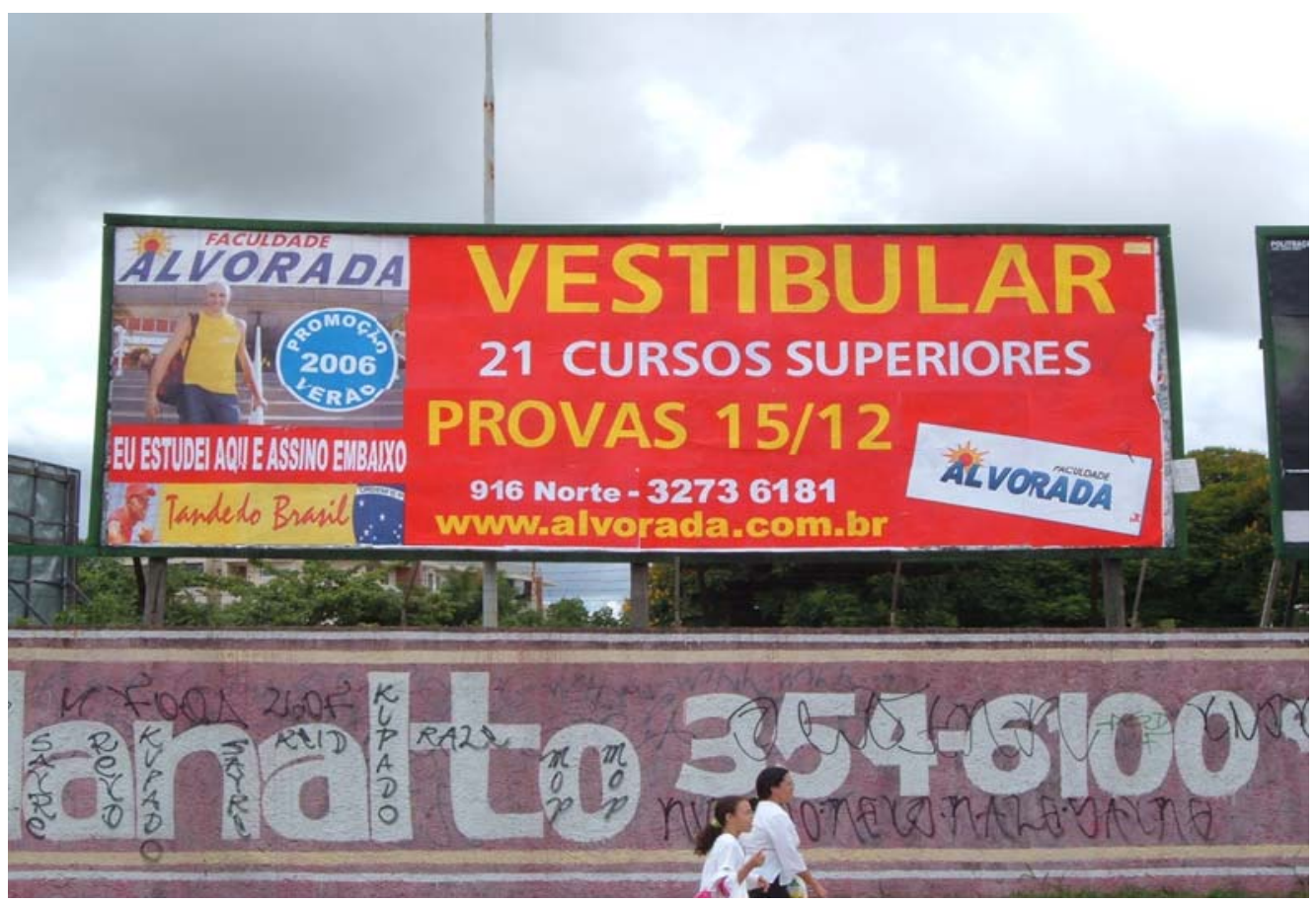

Ilustração 2 - Instituto de Ensino Superior de Brasília - IESB

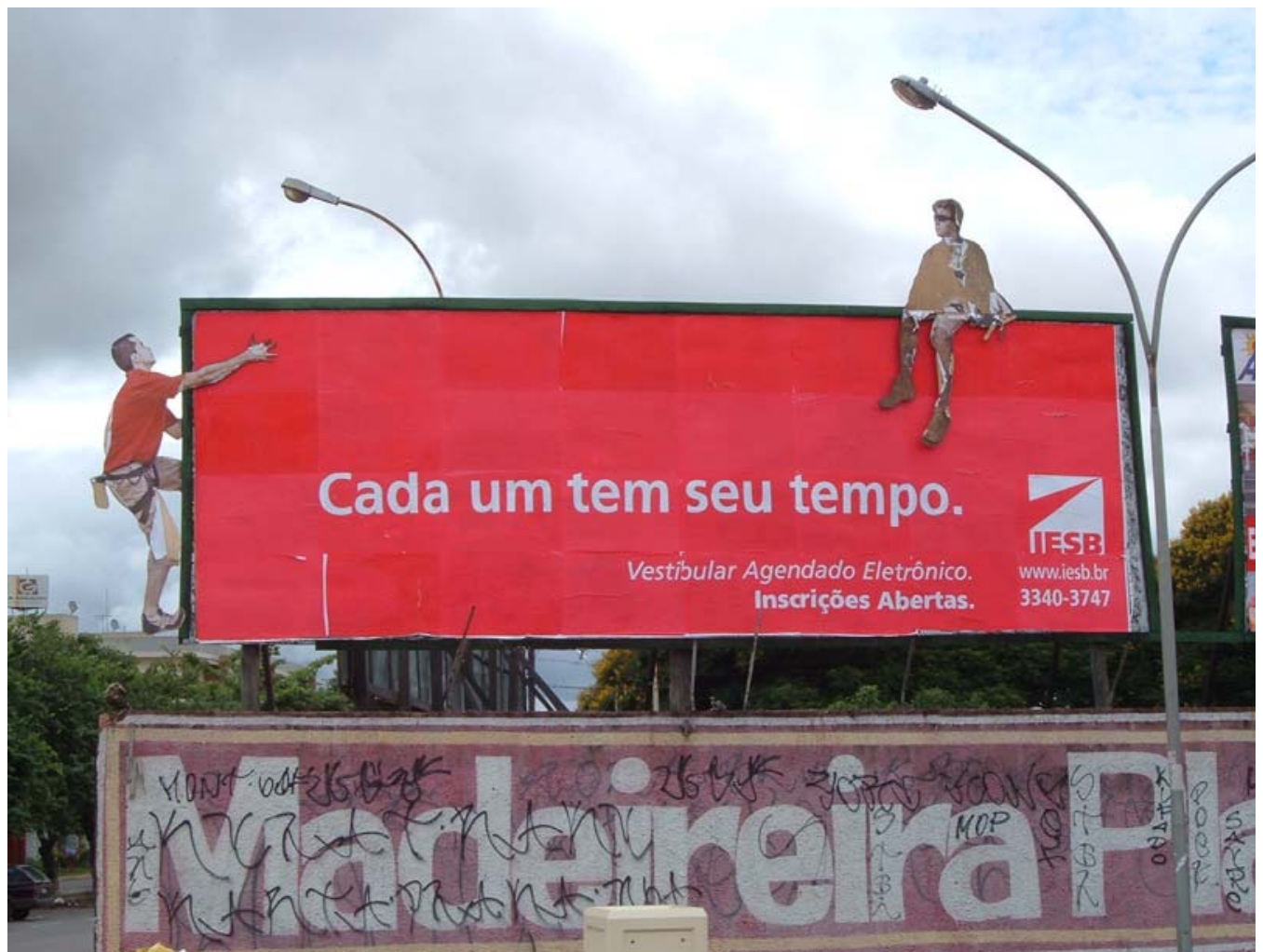


Ilustração 3 - Instituto de Ensino Superior de Brasília - IESB

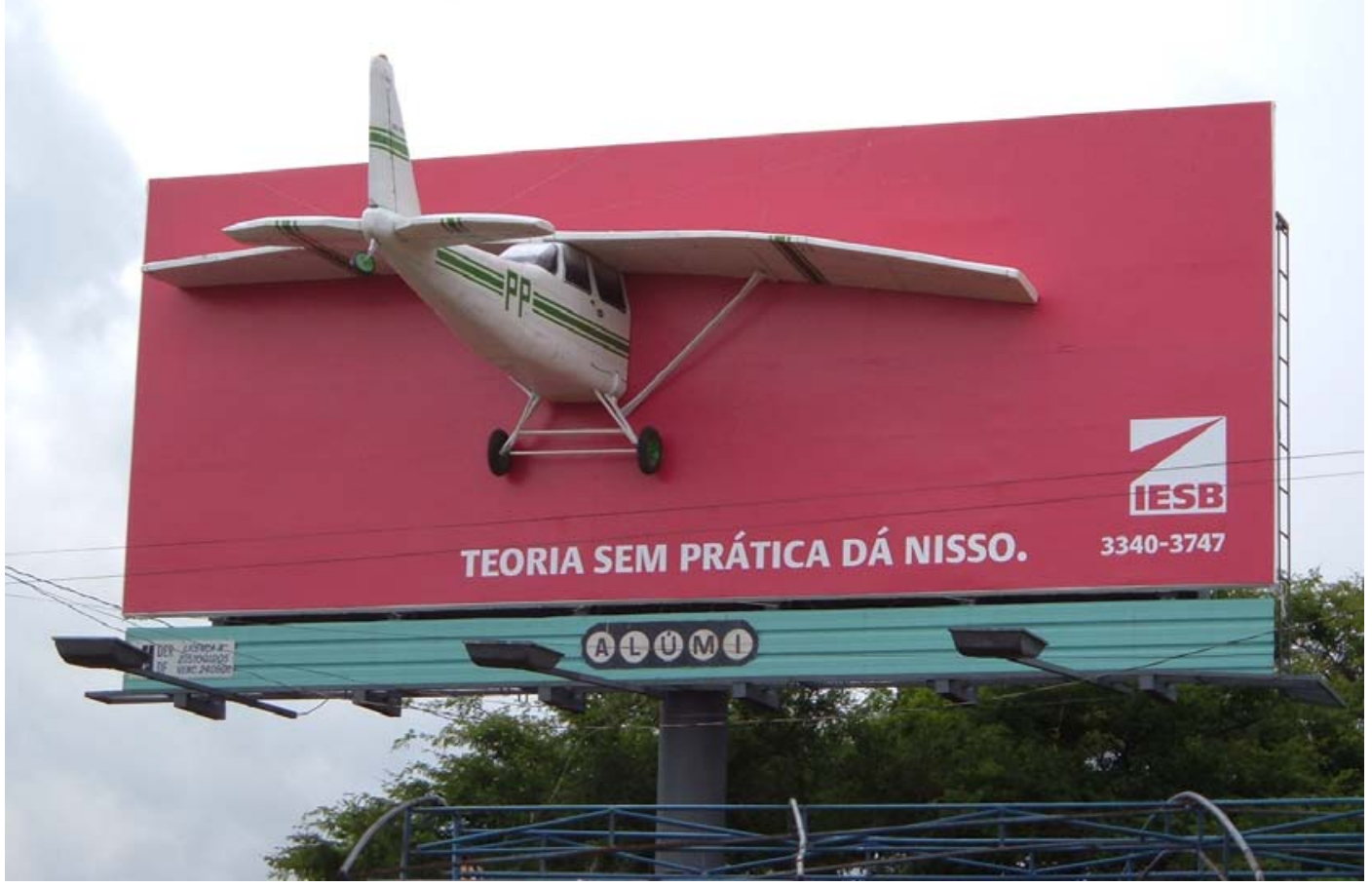

Ilustração 4 - Faculdade Michelangelo

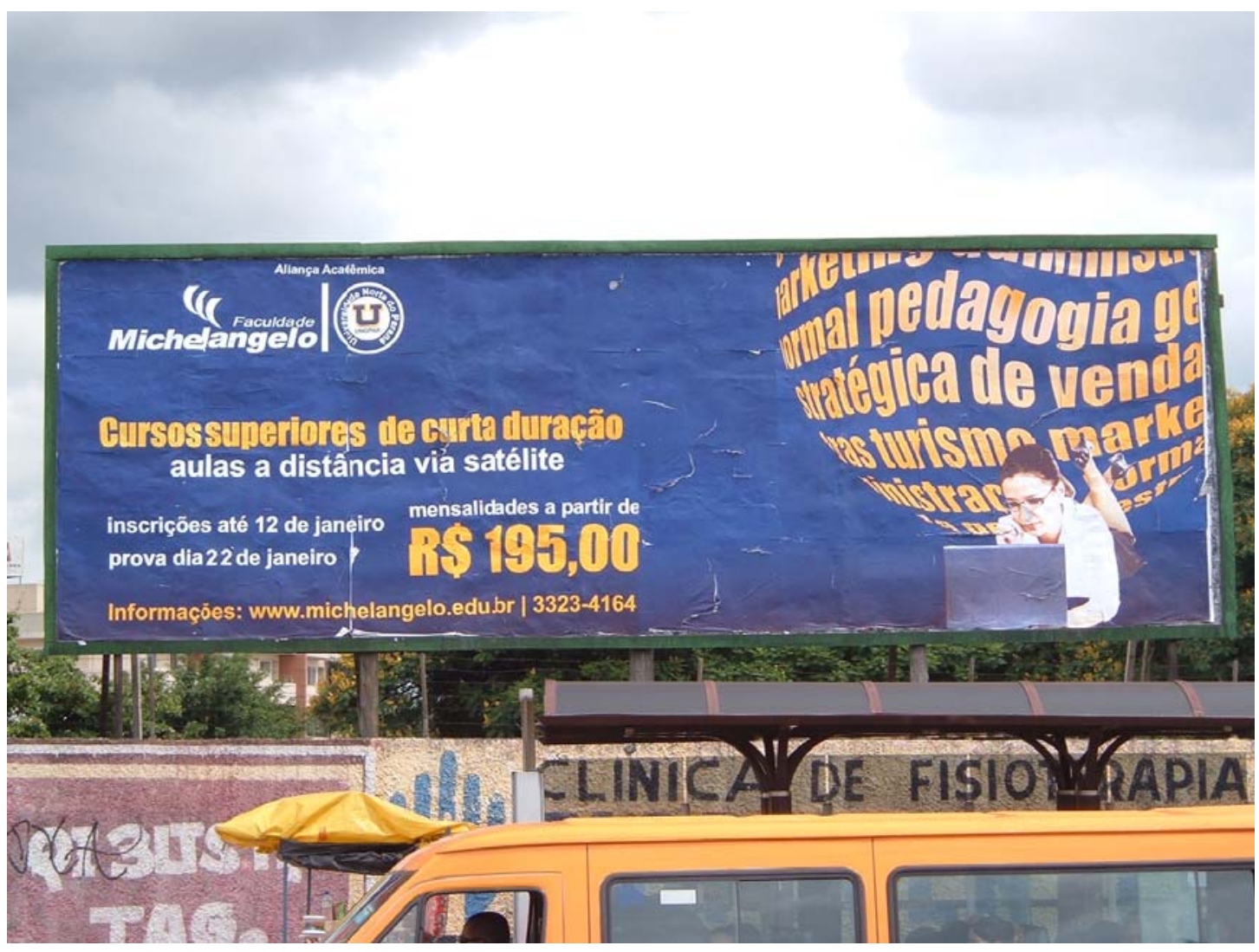


Ilustração 5 - Faculdade de Ciências de Brasília - FACIBRA

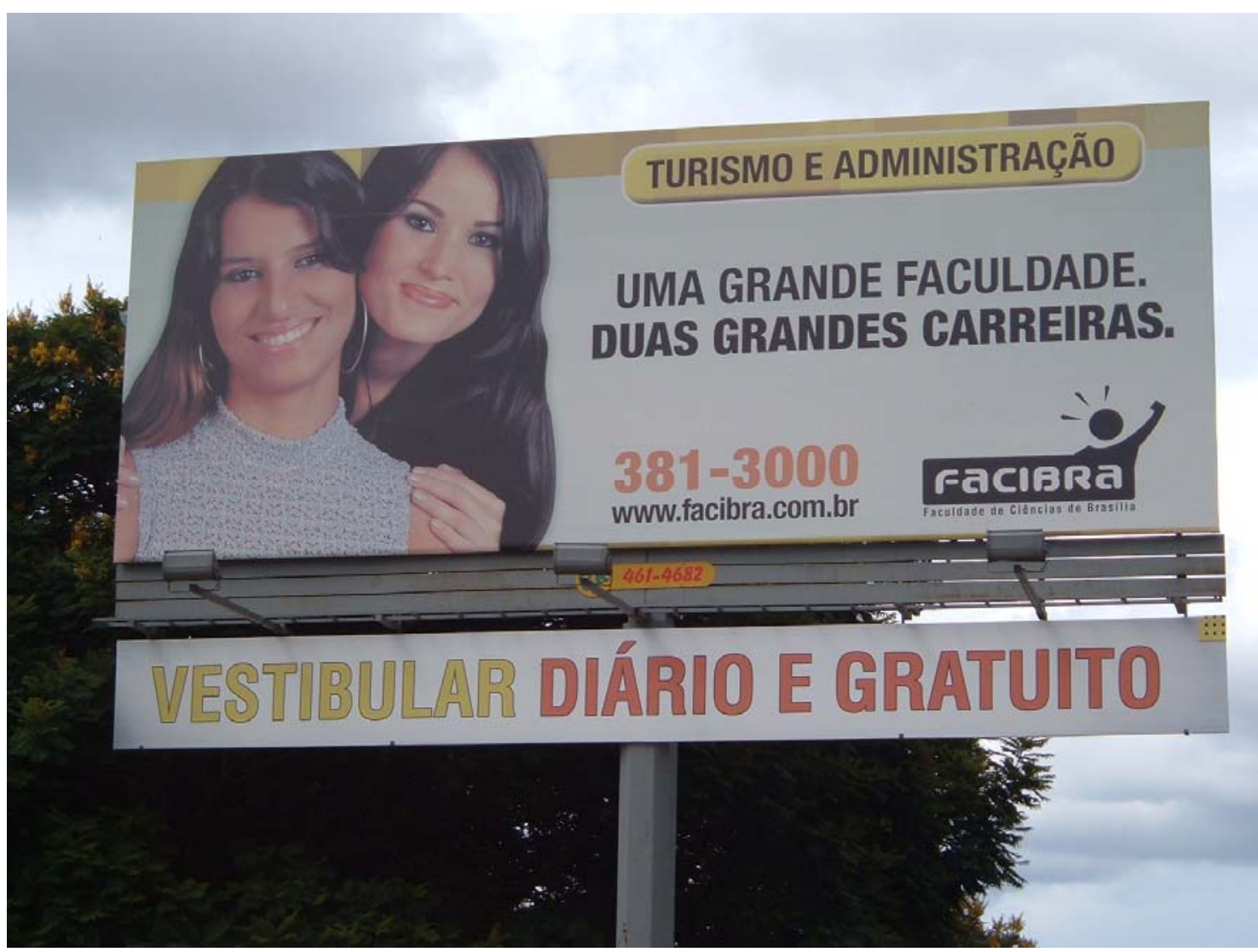

Ilustração 6 - Universidade Paulista - UNIP

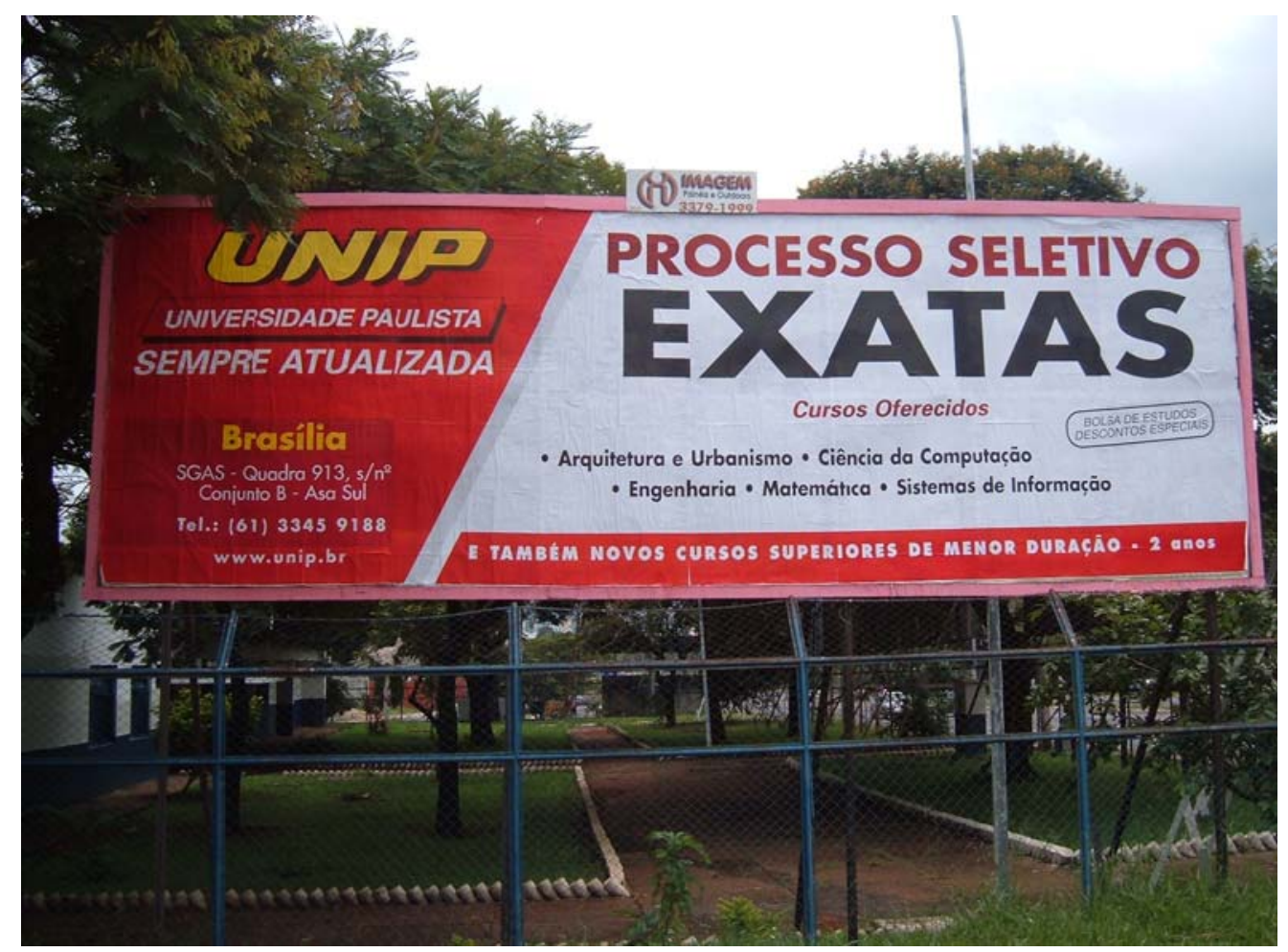


Ilustração 7 - Centro Universitário UNIEURO

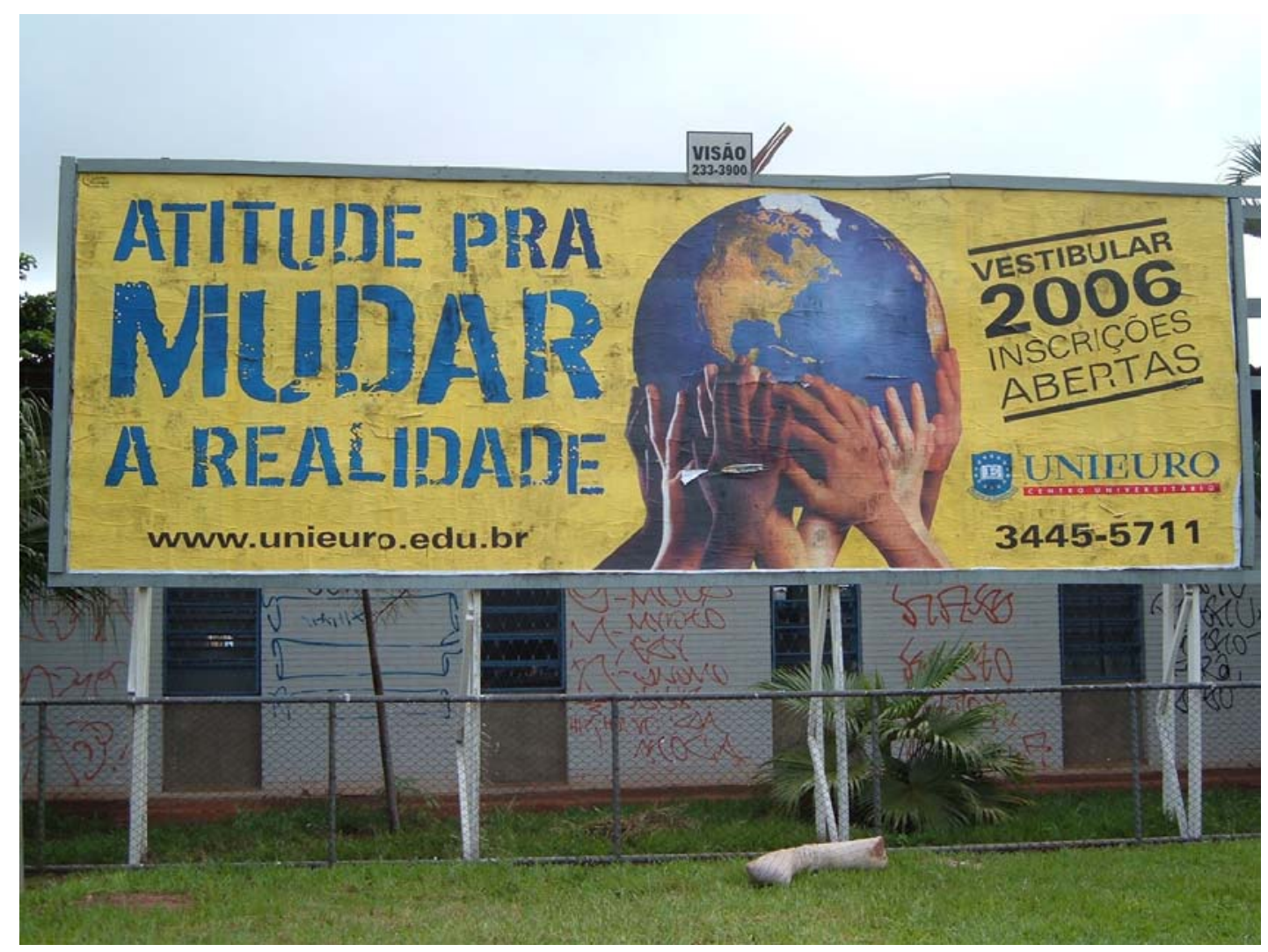

Ilustração 8 - Centro Universitário UNIEURO

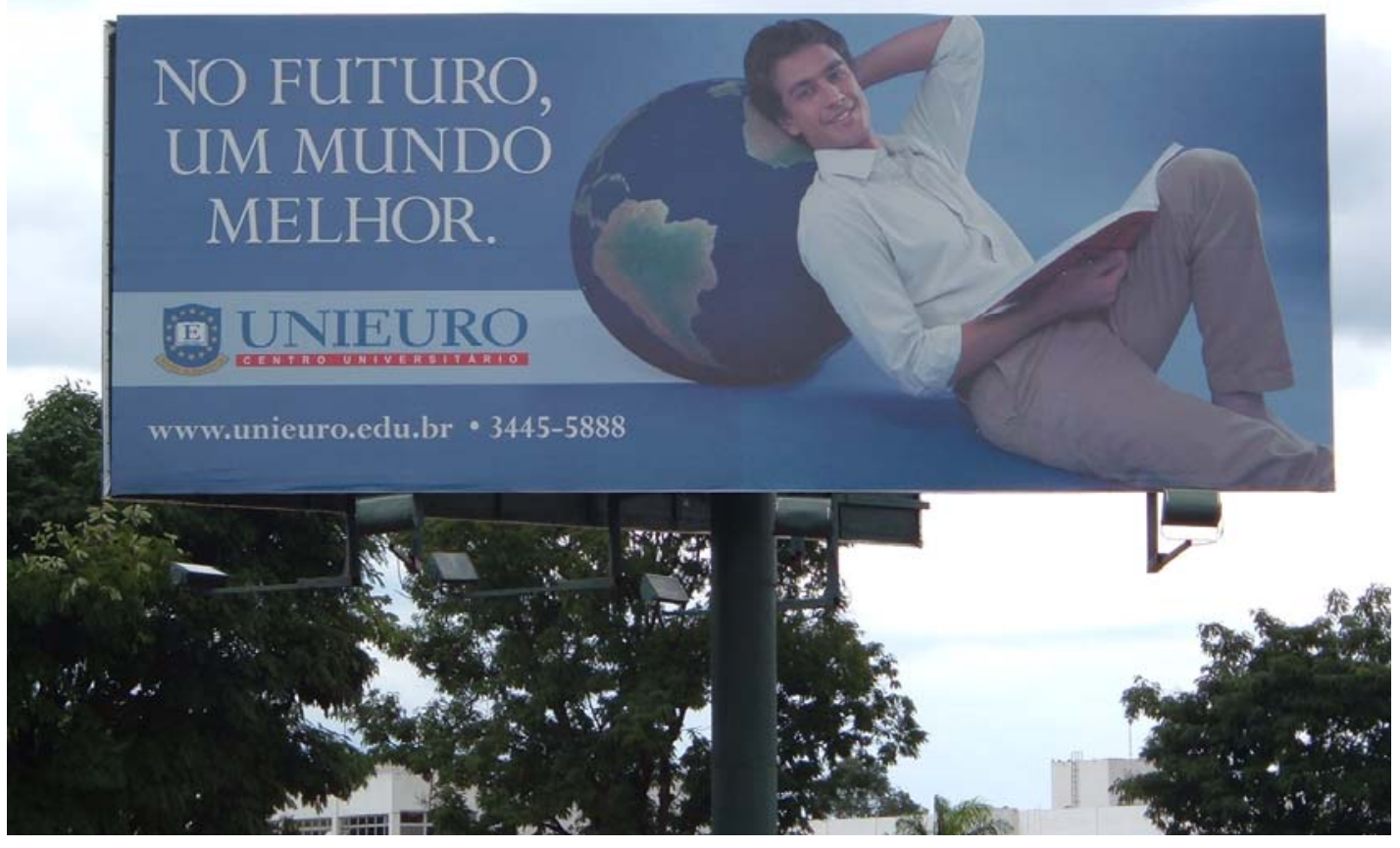


Ilustração 9 - União pioneira de Integração Social - UPIS

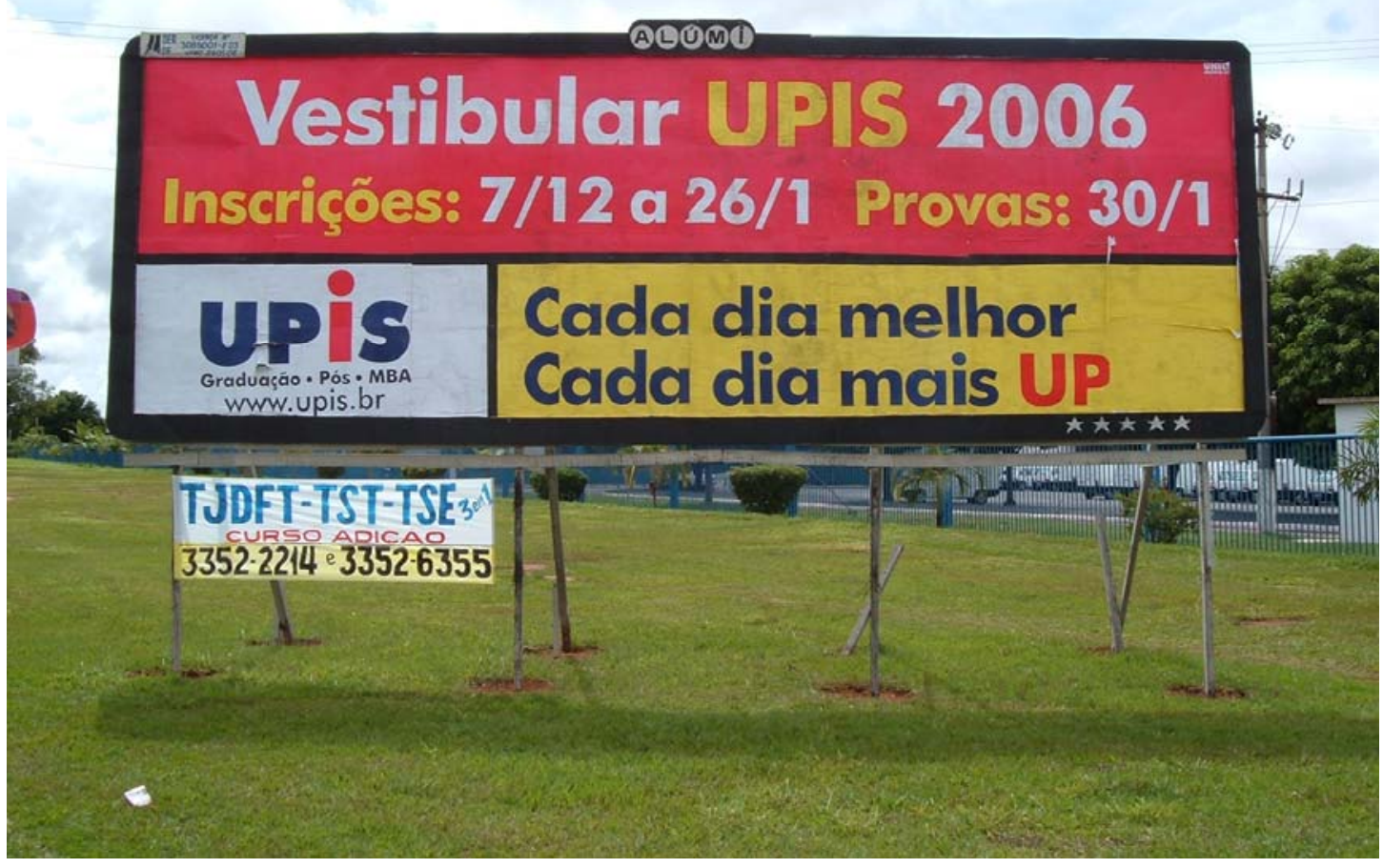

Ilustração 10 - Centro Universitário de Brasília UNICEUB

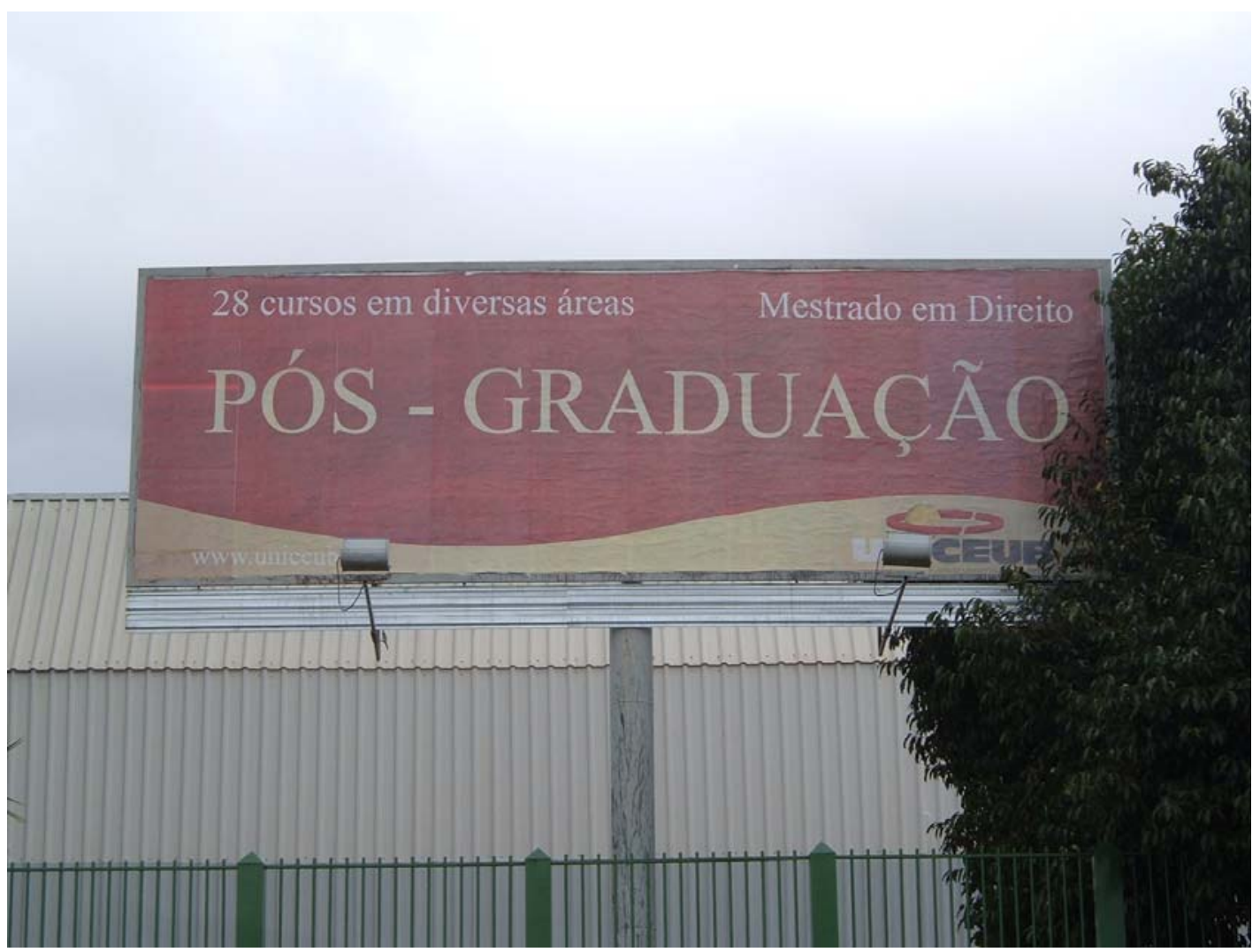




\section{ANEXO II}

Ilustração 11 - Faculdades Integradas da Terra de Brasília - FTB

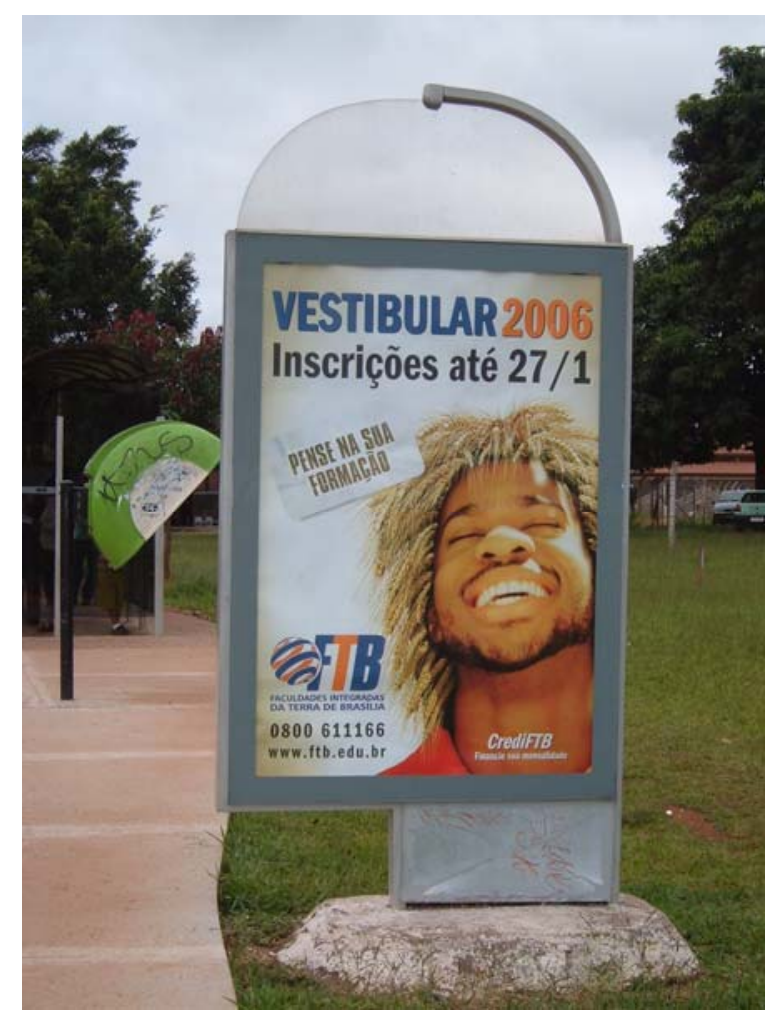

Ilustração 12 - Centro de Excelência em Turismo - CET

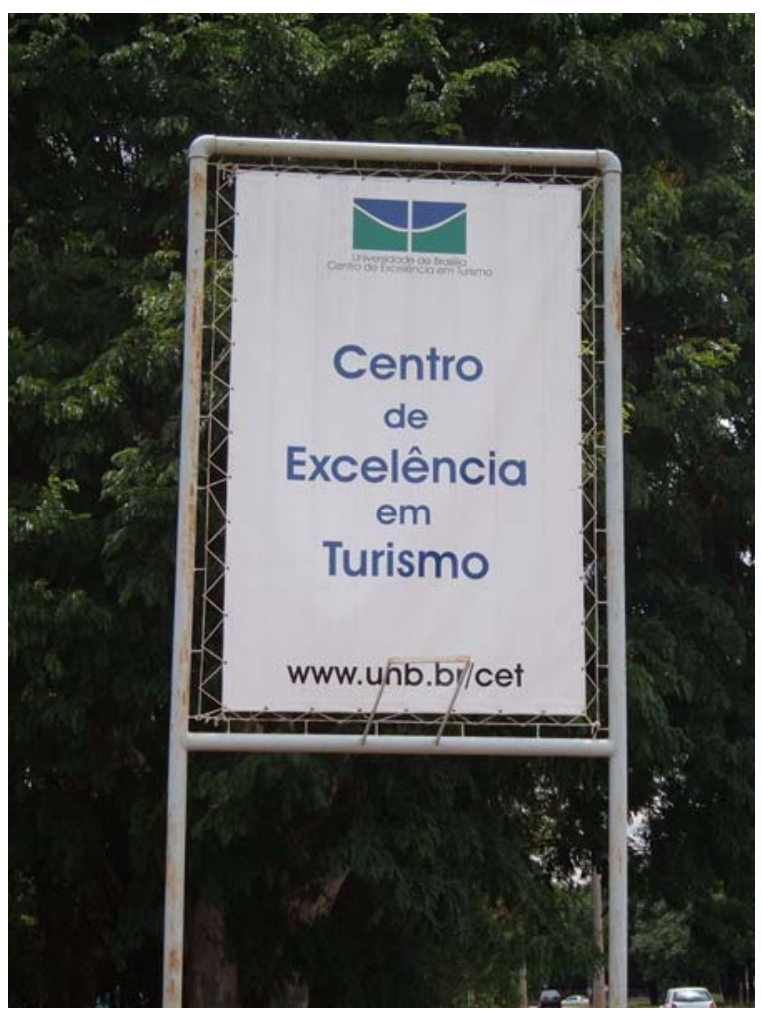


Ilustração 13 - Instituto de Educação Superior de Brasília - IESB

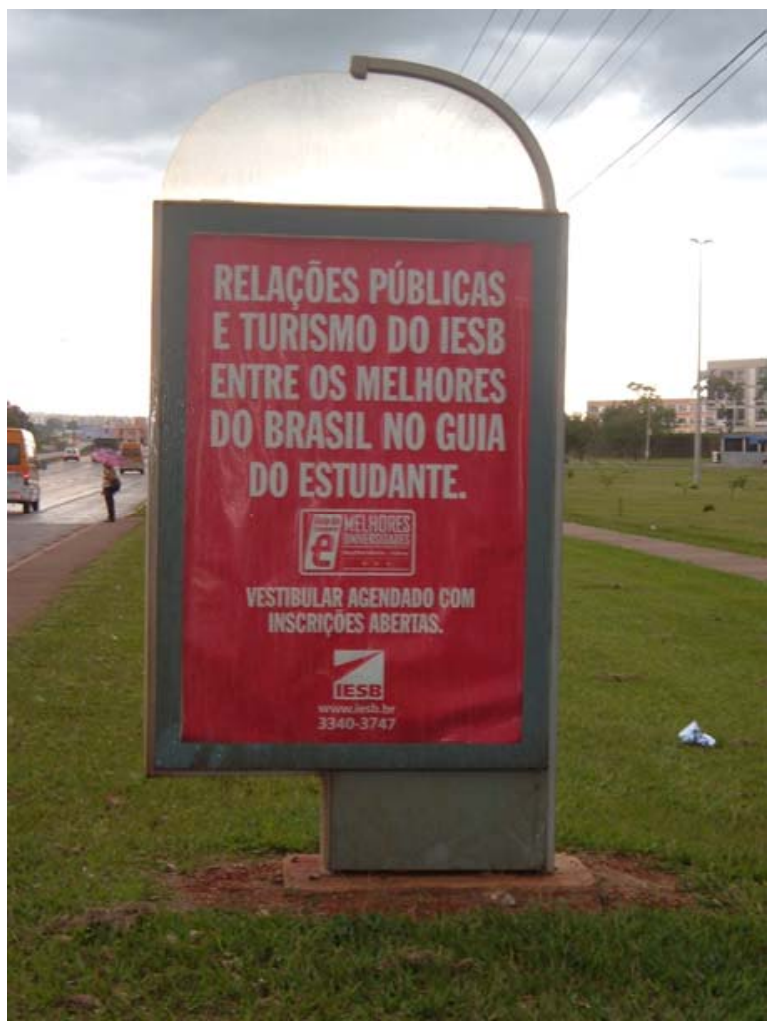

Ilustração 14 - União Pioneira de Integração Social - UPIS

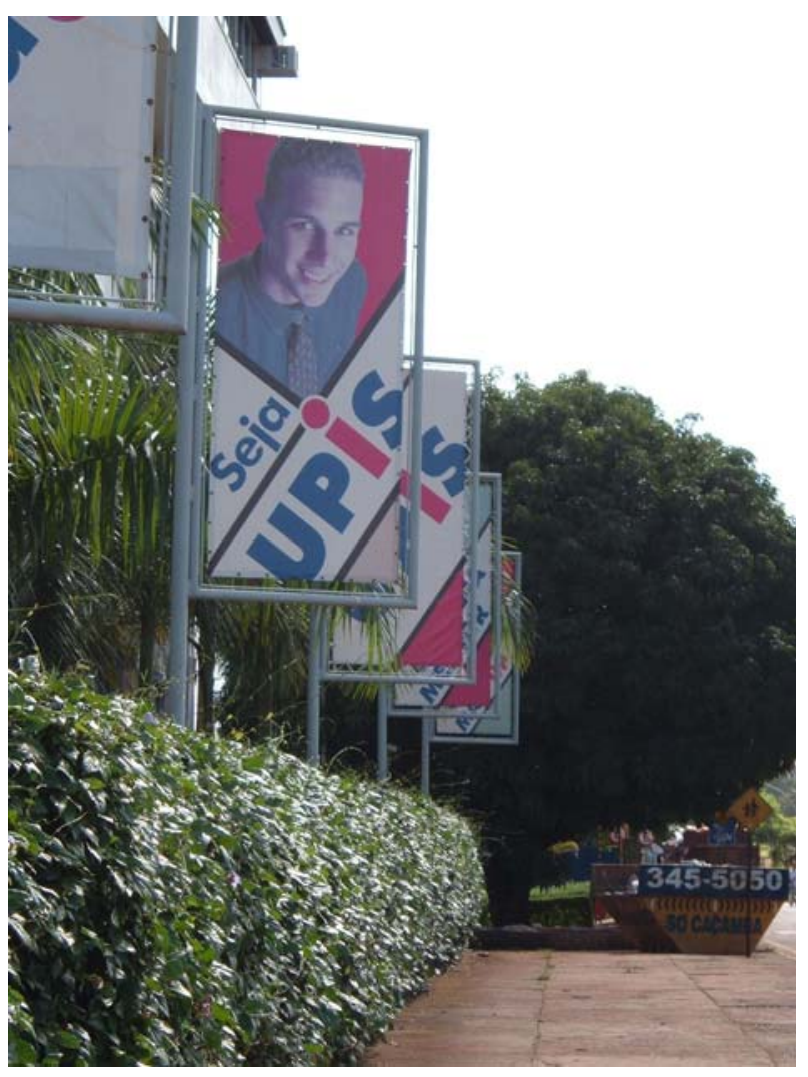




\section{ANEXO III}

Ilustração 15 - Stand no Shopping Center

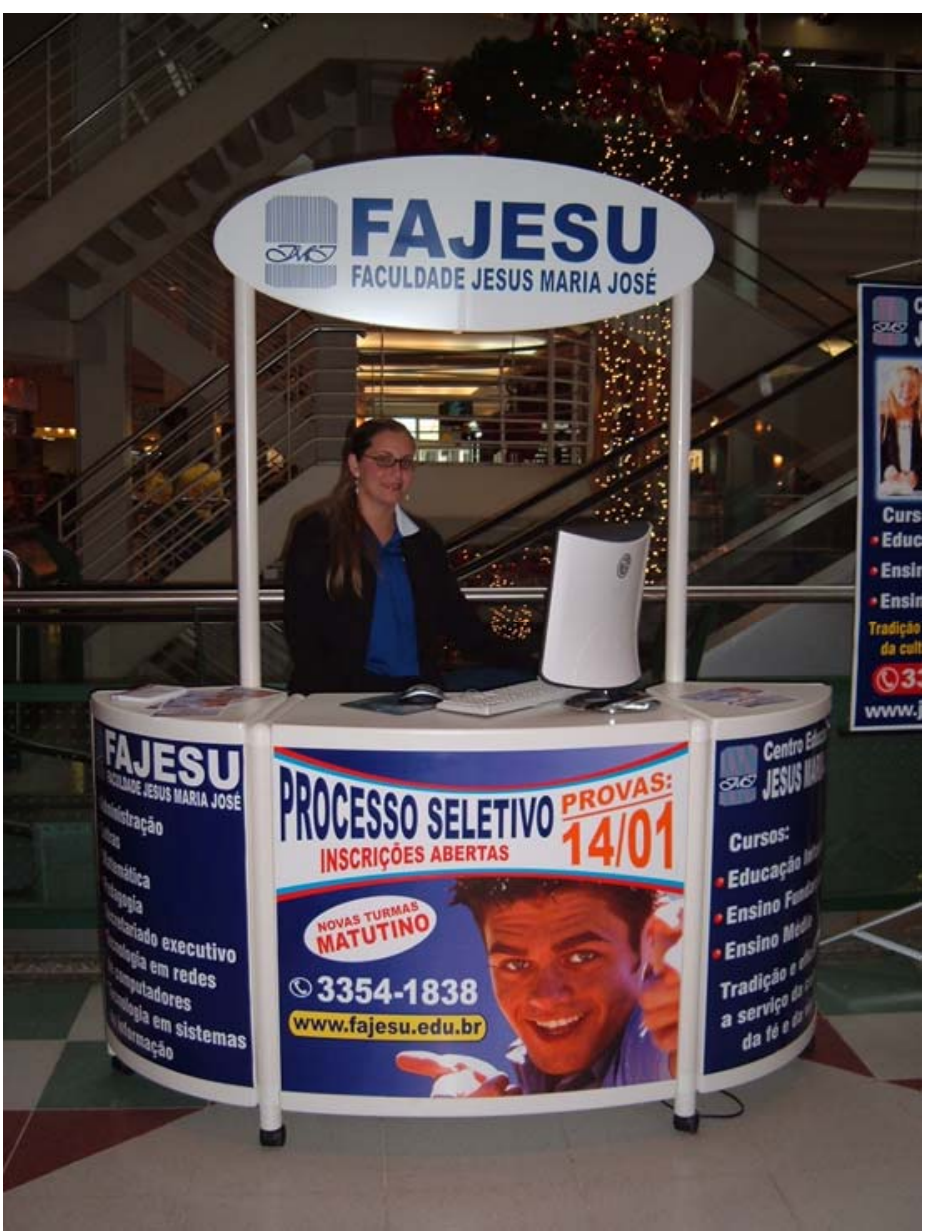

